\title{
EDUCACÃO BáSICA NA AMÉRICA LATINA: UMA ANÁLISE DOS ÚLTIMOS DEZ ANOS A PARTIR DOS DADOS DO PROGRAMA INTERNACIONAL DE AVALIAÇÃ̃O DE ESTUDANTES (PISA)
}

\author{
BASIC EDUCATION IN LATIN AMERICA: AN ANALYSIS OF THE LAST TEN YEARS FROM THE \\ DATA OF THE PROGRAMME FOR INTERNATIONAL STUDENT ASSESSMENT (PISA)
}

\author{
Recebido em 31.08.2017. Aprovado em 28.09.2017 \\ Avaliado pelo sistema double blind review \\ DOI: http://dx.doi.org/10.12712/rpca.v11i4.1065
}

\section{Bruno Francisco Batista Dias}

Universidade Federal Fluminense (UFF), Volta Redonda/RJ, BRASIL

brunofbd@id.uff.br

\section{Sandra Regina Holanda Mariano}

Universidade Federal Fluminense (UFF), Niterói/RJ, BRASIL

sandramariano@id.uff.br

\section{Robson Moreira Cunha}

Universidade Federal do Rio de Janeiro (UFRJ), Rio de Janeiro/RJ, BRASIL

robsoncunha@id.uff.br

\begin{abstract}
Resumo
Este artigo analisou a qualidade da educação pública em sete países da América Latina que participam do Programa Internacional de Avaliação de Estudantes (PISA) no período compreendido entre os anos de 2006 a 2015. O estudo correlacionou o desempenho dos estudantes na faixa de 15 anos da Argentina, Brasil, Chile, Colômbia, México, Peru e Uruguai, com o índice de status econômico, social e cultural desses países. Empregou-se o método estatístico de regressão linear multivariável, ajustada pelo método dos mínimos quadrados (MMQ). Buscou-se identificar os fatores que influenciam desempenho do PISA na amostra selecionada. A análise descritiva dos resultados apontou para importantes melhorias, principalmente na redução das desigualdades de desempenho em linguagem, matemática e ciências e de características socioeconômicas dos estudantes avaliados. Os resultados dos sete países apontam uma significativa melhora na capacidade dos seus estudantes em leitura, principalmente no Peru e Chile. À exceção do Chile, o conhecimento em matemática apresentado pelos estudantes latino-americanos encontra-se nos níveis iniciais de proficiência, suficiente apenas para interpretar resultados e raciocinar diretamente sobre as questões apresentadas ou responder perguntas simples as quais estão contextualizados. Em ciências, estudantes do Peru e do Brasil obtiveram 100 pontos abaixo da média dos seus pares da OCDE, indicando apenas capacidade de aplicação do conhecimento científico em situações nas quais já estão familiarizados. As conclusões apontaram que os últimos dez anos os fatores socioeconômicos foram capazes de explicar 14,1\% do desempenho do PISA para os países analisados, sendo essa influência maior no Peru e menor na Argentina.
\end{abstract}

Palavras-chave: PISA. América Latina. Políticas Públicas de Educação. Educação Básica.

\begin{abstract}
This article addresses the issue of the quality of public education in Latin America, specifically for seven countries in this region: Argentina, Brazil, Chile, Colombia, Mexico, Peru and Uruguay. The performance of these nations was adopted as an educational quality metric in PISA - Programme for International Student Assessment, which measures the performance of students in the 15 years of science, reading and mathematics. Considering that the performances obtained by the students of this region are situated in the lower levels of performance, the study had as purpose to evaluate the influence of the socioeconomic factors on these results. Thus, we sought to analyze the correlation between the PISA result and the Economic, Social and Cultural Status Index (ESCS) of these countries in the period from 2006 to 2015. The statistical method of linear regression was used, with SPSS software support. The obtained results were presented through a linear model defined by the equation of a line adjusted by the method of the least squares and illustrated in the form of dispersion diagrams, being also individualized by disciplines evaluated. The descriptive analysis of the results pointed to important improvements, mainly in reducing the inequalities of performance and socioeconomic characteristics of the evaluated students. The conclusions showed that, on average, socioeconomic factors account for $14 \%$ of students' performance in the evaluation, being this influence greater in Peru and lower in Argentina.
\end{abstract}

Keywords: PISA. Latin America. Public Education Policies. Basic Education. 


\section{Introdução}

O nível de desempenho acadêmico dos estudantes da educação básica é considerado um fator determinante para a competitividade de um país (OECD, 2015). Melhores níveis de aprendizagem estão associados a índices mais elevados de produtividade da força de impactando positivamente o desenvolvimento nacional. O reconhecimento da educação como fator central para o desenvolvimento dos países levou a Organização para Cooperação e Desenvolvimento Econômico (OCDE) a criar o Programa Internacional de Avaliação de Estudantes - PISA, visando aferir o conhecimento de jovens em linguagem, matemática e ciências. Trata-se de uma iniciativa de avaliação comparada, aplicada a estudantes na faixa dos 15 anos, idade em que se pressupõe o término da escolaridade básica obrigatória na maioria dos países (OECD, 2015). Participam da iniciativa os países membros da OCDE e outras nações convidadas. Os resultados obtidos têm subsidiado a formulação de políticas públicas no campo da educação e influenciado, sobremaneira, o debate sobre o tema.

O PISA é realizado desde 2000 e aplicado a cada três anos. Além dos resultados dos exames, seus dados também contemplam um conjunto de informações que permitem compreender os contextos, as políticas educacionais, e as características socioeconômicas em que os exames foram realizados. Essas informações são obtidas através de um conjunto de questionários direcionados ao aluno, à escola e aos familiares. Permitindo, assim, análises que relacionem o desempenho estudantil e a realidade local.

Em 2015, a aplicação do PISA aconteceu no mês de maio para estudantes selecionados, por amostragem, distribuídos em 70 países e territórios. A avaliação envolveu, aproximadamente, $500 \mathrm{mil}$ estudantes nascidos no ano de 1999. Na América Latina, os sete países analisados, e que participam regularmente do exame desde 2000, foram: Argentina, Brasil, Chile, Colômbia, México, Peru e Uruguai. (INEP, 2015)

Apesar dos esforços despendidos na reformulação de políticas públicas educacionais na última década, os resultados dos países da América Latina na última avaliação do PISA, em 2015, mostram grande distância separá-los dos países desenvolvidos. Isto é, muito ainda precisa ser feito e reformulado para que a realidade da educação brasileira e latino-americana se equipare aos dos países que ocupam as melhores classificações no ranking da OCDE.
Em outros termos, os países latino-americanos estão nas últimas posições no ranking mundial do PISA, juntos com os países do norte da África. Segundo Hanushek e Woessmann (2012) o baixo nível de desempenho dos estudantes dessa região foram os fatores determinantes para crescimentos econômicos inferiores aos demais países do mundo nas últimas quatro décadas. Outros estudos na área de economia da educação, também apontam no mesmo sentido - de que o nível de qualidade do capital humano resultante das políticas educacionais são fatores primordiais ao desenvolvimento econômico e a falta de uma educação de qualidade implica em sérios entraves para o desenvolvimento nacional (JAPELLING, 2010).

Diante da problemática exposta, este estudo se propõe a conhecer a realidade socioeconômica da educação pública básica dos sete países da América Latina que participam do PISA na última década, relacioná-las com os resultados obtidos no exame, e identificar possíveis fatores que podem explicar o desempenho observado nessa região. Sendo assim, o foco deste artigo consiste em prover informações que permitam comparar a realidade da educação dessas nações, tema que ainda é pouco discutido no campo da gestão.

Neste artigo, os dados da OCDE serão utilizados com o objetivo de escrutinar os resultados do PISA nos países da América Latina, mostrando a sua evolução, considerando o período de 2006 a 2015. Apesar da limitação da análise, uma vez que os países da América Latina participam apenas esporadicamente dos testes, este trabalho apresenta um esforço inicial de analisar de forma contextualizada a educação básica em países da América Latina nos últimos dez anos.

Para atingir os fins pretendidos, este artigo está estrutura em cinco seções, sendo a primeira esta introdução. Em seguida, é apresentada uma discussão sobre o PISA, seguida de um apanhado das políticas públicas de educação implementada nos países selecionados. $\mathrm{Na}$ sequência, apresenta-se e discute-se a metodologia de pesquisa adotada, bem como os resultados obtidos. Por fim, são apresentadas as conclusões e elementos para subsidiar pesquisas futuras.

\section{O Programa Internacional de Avaliação de Estudantes (PISA)}

A Organização para a Cooperação e Desenvolvimento Econômico (OCDE) foi fundada em 1967, sob a 
liderança dos Estados Unidos da América (EUA) e da Grã-Bretanha, como desdobramento das ações multilaterais do pós-guerra. Para a OCDE, a harmonia e a prosperidade dos países deriva, em grande medida, da qualidade do seu capital humano. Neste sentido, para que os países alcancem uma posição competitiva em um mundo em rápida transformação, os indivíduos precisam incorporar, ao longo de suas vidas, novos conhecimentos e habilidades (OECD, 2004).

Esta visão é claramente influenciada pela teoria do capital humano que oferece o suporte teórico para as políticas adotadas e promovidas pela OCDE, alçando a educação ao topo das prioridades das ações da instituição. A OCDE declarou que "as habilidades se tornaram a moeda global das economias do século XXI" (OECD, 2012, p. 10). Sendo assim, as questões relativas à educação e ao treinamento ganharam papel de destaque e tornam-se objetos centrais das intervenções de políticas públicas que devem ser aprimoradas, tanto para garantir o bem-estar dos indivíduos como para a solidez econômica das nações.

Com base nesta premissa, a Diretoria de Educação da OCDE formulou, em 1997, o Programa Internacional de Avaliação de Alunos (Programme for International Student Assessment - PISA), com o objetivo de contribuir para a elevação do capital humano dos países, definido pelas "habilidades de conhecimento, competências e atributos incorporados em indivíduos que facilitem a criação de bem-estar pessoal, social e econômico “(OECD, 2001, p. 18).

Os formuladores do PISA acreditavam que as evidências sobre o desempenho de leitura, matemática e ciências coletadas de uma amostra aleatória de estudantes de 15 anos, de cada país participante do exame, ofereceriam uma análise comparativa dos sistemas educacionais e sua evolução ao longo do tempo (OECD, 2004). A análise e interpretação dos resultados do PISA, de fato, tem permitido o monitoramento do progresso dos estudantes de cada país participante, bem como a identificação das forças e fraquezas dos sistemas educacionais.

Um dos objetivos da OCDE é justamente estimular os países a elevarem suas expectativas sobre a educação oferecida à sociedade e para isso oferece evidências sobre as quais as políticas nacionais de educação, os currículos escolares, a formação e professores, entre outros aspectos, podem ser aprimorados.

Carvalho (2016) destaca que os resultados do PISA vêm sendo utilizados por diferentes atores tais como: políticos, formuladores de políticas públicas, jornalistas, pesquisadores, especialistas, técnicos e gestores educacionais. Cada um os utiliza a sua maneira para investigar, problematizar e subsidiar debates e políticas na área de educação. Os resultados dos testes têm sido utilizados também para legitimar as políticas públicas implementadas em diversos sistemas educacionais, oferecendo uma base de apoio e um crivo técnico para a tomada de decisão. $\mathrm{O}$ autor enfatiza o caráter de regulação política e social dos sistemas educativos ao qual o PISA foi alçado.

"Esse conjunto de observações sobre a presença do PISA nos contextos nacionais, pela mão de diferentes utilizadores (políticos e outros atores envolvidos nos debates públicos sobre educação, peritos e investigadores nacionais), permite dizer que os materiais providenciados pelo PISA são reinterpretados, tornando-se aceitáveis e eficazes para cada contexto social e cognitivo que os recebe. Tal variedade não é um sinal de fraqueza, mas é o principal sinal da força do PISA como instrumento de regulação, na justa medida em que as divergências verificadas no uso dado ao PISA coexistem com uma convergência para o uso do PISA. É esta manifestação do seu "efeito de agregação": as controvérsias, as ficções ou os escrutínios dos sistemas, das políticas e das práticas educacionais são feitas em comprometimento com os seus resultados ou com os seus referenciais. Dito de outro modo, a força do PISA reside na sua compreensão e aceitação como um recurso que é percebido como natural e inevitável para a ação política no setor educativo. " (Carvalho, 2016, p. 676)

A influência do PISA é crescente, apesar das contestações de ordem epistemológica, metodológica, ou mesmo, política. Gorur (2016), por exemplo, critica a limitação dos elementos que formam o banco 
de dados do PISA e o seu uso em análises secundárias que, para o autor, ficam limitadas pela padronização e simplificação dos dados. Há também críticas de ordem política, apontando que o conceito de globalização adotado pela OCDE implica uma visão neoliberal do mundo, negando outras abordagens e processos (SELLAR, LINGARD, 2014).

Fato é que em torno do PISA se desenvolveu uma comunidade epistêmica envolvida com a difusão, troca e produção de conhecimento. Para Morgan et. al. (2014) a OCDE criou suas próprias comunidades epistêmicas assegurando a validação de sua capacidade técnica e perícia no campo da educação.

A posição conquistada pela OCDE como uma das mais importantes e influentes instituições da área de educação é demostrada pela expansão do PISA no que se refere ao seu escopo e abrangência. Selllar e Lingard (2014) assinalam, que em 2000, a primeira edição da avaliação contou com a participação de vinte e oito membros da OCDE e quatro países não membros, entre eles o Brasil. Em 2012, os 34 países membros da OCDE participaram, juntamente com 30 países não-membros. O alcance do PISA se estendeu para novas regiões da Ásia, além da cidade de Shangai, Coreia do Sul e Singapura, da África do Norte e do Golfo Árabe, e de cada um dos países BRIC (Brasil, Rússia, Índia e China).

"A OCDE tem procurado
aumentar a influência do PISA ao
longo do seu ciclo de vida, uma
"expansão" que envolveu três
tipos de alterações: a ampliação do
espaço geopolítico do inquérito;
o alargamento dos objetos e dos
sujeitos que são avaliados pelo
PISA; o alargamento do seu poder
explicativo, isto é, a criação de
novos modos de usar os dados
de modo a alargar a influência do
conhecimento proporcionado pelo
PISA na decisão política." (Selllar e
Lingard, 2013, p. 677)

O PISA é administrado a cada três anos, de modo que o desempenho dos países pode ser acompanhado ao longo do tempo. Para cada ciclo de avaliação uma das três áreas de teste é selecionada como o principal domínio, sendo as duas outras avaliadas com menor ênfase. Nos primeiros três ciclos do PISA (2000, 2003 e 2006) foram enfatizados respectivamente a leitura, a matemática e a ciência. O mesmo padrão foi adotado nos ciclos de 2009, 2012 e 2015.

Um exemplo de ampliação do escopo do teste foi a criação do PISA para o Desenvolvimento (PISA-D), em 2013, construído especificamente para ser adotado em países 'renda baixa e média' (ADDEY, 2016). A autora discute a importância da realização do teste considerando os contextos destes países, que poderão produzir dados politicamente mais relevantes para os seus sistemas educacionais. A iniciativa contou com participação ativa de países da América do Sul, como Equador e Paraguai. Nos ciclos recentes, o PISA também incluiu opções para avaliações adicionais, como alfabetização financeira e resolução de problemas, por exemplo. Alguns países da América Latina vêm participando do PISA desde 2000, como países não-membros, como é o caso do Brasil.

Os resultados do PISA indicam até seis níveis de conhecimento e habilidades que os estudantes possuem em determinada área que fora avaliada. Ao alcançar determinado nível, significa que os estudantes possuem um determinado conjunto de habilidades e que são capazes de realizar um conjunto de as tarefas importantes para a vida adulta. A escala representativa dos níveis de conhecimento por desempenho em leitura pode ser observada na Tabela 1.

Tabela 1 . Níveis de desempenho no PISA em leitura

\begin{tabular}{|l|l|}
\hline Nível & Desempenho no PISA \\
\hline Quinto & Acima de 625 \\
\hline Quarto & De 553 até 625 \\
\hline Terceiro & De 481 até 552 \\
\hline Segundo & De 408 até 480 \\
\hline Primeiro & De 335 até 407 \\
\hline
\end{tabular}

Fonte: OECD (2015)

Os níveis de aprendizagem descritos na Tabela 1 indicam a capacidade dos estudantes no domínio de leitura. O nível mais alto, referentes a valores acima de 625 , corresponde dizer que os estudantes possuem capacidade sofisticada de entender, interpretar e encontra informações úteis em textos de difícil entendimento. No nível 4, estão situados os alunos com capacidade avançada de leitura e interpretação. Os estudantes situados no nível 3 e 2 são aqueles capazes apenas de manipular de forma moderada e 
básica os níveis de leitura, respectivamente. No nível mais baixo, encontram-se aqueles cuja capacidade consiste apenas em estabelecer uma conexão simples do texto com o cotidiano. Resultados abaixo de 335 pontos indicam a incapacidade de executar tarefas básicas de leitura (OECD, 2015).

Os níveis de conhecimento relacionados ao desempenho em matemática podem ser observados na Tabela 2.

Tabela 2 . Níveis de desempenho no PISA em matemática

\begin{tabular}{|l|l|}
\hline Nível & Desempenho no PISA \\
\hline Sexto & Acima de 669 \\
\hline Quinto & De 607 até 668 \\
\hline Quarto & De 444 até 606 \\
\hline Terceiro & De 482 até 443 \\
\hline Segundo & De 420 até 481 \\
\hline Primeiro & De 357 até 419 \\
\hline
\end{tabular}

Fonte: OECD (2015)

Neste indicador, o sexto nível, que compreendem os valores acima de 669, indicam pensamento e raciocínio matemático avançado, e capacidade de investigação e modelagem de problemas complexos. $\mathrm{O}$ $5^{\circ}$ nível indica capacidade de compreender, formular e expressar soluções de problemas complexos. Aqueles situados no $4^{\circ}$ nível possuem moderada capacidade de entender modelos matemáticos e raciocinar com certa compreensão sobre a temática. Estar situando no $3^{\circ}$ ou $2^{\circ}$ níveis indicam que os alunos conseguem apenas interpretar literalmente resultados e raciocinar diretamente sobre as questões apresentadas. No $1^{\circ}$ nível, os estudantes apenas são capazes de responder perguntas simples as quais estão contextualizados. Desempenhos abaixo de 357 pontos indicam a incapacidade de solucionar questões básicas no domínio da matemática (OECD, 2015).

Em ciências, os níveis de aprendizagem são distribuídos conforme descrito na Tabela 3.

Tabela 3 . Níveis de desempenho no PISA em ciências

\begin{tabular}{|l|l|}
\hline Nível & Desempenho no PISA \\
\hline Sexto & Acima de 669 \\
\hline Quinto & De 607 até 668 \\
\hline Quarto & De 444 até 606 \\
\hline Terceiro & De 482 até 443 \\
\hline Segundo & De 420 até 481 \\
\hline
\end{tabular}

\begin{tabular}{|l|l}
\hline Primeiro & De 357 até 419
\end{tabular}

Fonte: OECD (2015)

Quanto à aprendizagem em ciência, o nível mais elevado, acima de 669, engloba os estudantes capazes de explicar, aplicar e entender uma grande variedade de situações complexas do cotidiano envolvendo o conteúdo científico. No nível 5 , os estudantes são capazes de entender e solucionar várias situações da vida que envolva o conteúdo analisado. Os estudantes situados no nível 4 são aqueles que conseguem refletir sobres suas ações aplicando os conteúdos. No nível 3 e 2 situam-se aqueles que pelo menos conseguem tomar decisões e interpretar problemas tecnológicos. No nível mais baixo, os estudantes possuem limitado conhecimento científico, e apenas conseguem aplicálos em situações familiares (OECD, 2015).

Além da divulgação do desempenho dos estudantes, um dos grandes avanços trazidos pela OCDE foi a divulgação dos resultados em conjunto com as informações do contexto educacional de cada país. A disponibilização desses dados permitiu melhor comparação entre os países participantes, e auxiliarem pesquisadores de várias partes do mundo (GUEDES, BAQUEIRO e LORDÊLLO, 2015, ADROGUE, 2013; HANUSHEK e WOESSMANN, 2012) a relacionarem o contexto socioeconômico com o desempenho estudantil. Nesse sentido, o principal indicador de contextualização do desempenho usado pelo PISA, desde 2000, é o índice de status econômico, social e cultural, da siga em inglês para PIS $A$ index of economic, social and cultural status (ESCS), que apresenta valores por escola e por aluno.

O ESCS é composto por outros três índices calculados com base nos questionários socioeconômicos aplicados a escola: a) o índice que mede o maior nível de ocupação dos pais ou highest occupational status of parents (HISEI), na sigla em inglês; b) o índice que mede o maior nível de educação dos pais ou parents education (PARED), medida em número de anos de educação formal ; c) o índice que mede a riqueza familiar, bens culturais e recursos educacionais em casa ou home possessions (HOMEPOS) . Por definição o índice ESCS assume o valor inicial 0, que consiste na média dos fatores socioeconômicos dos países que foram avaliados, variando no intervalo da escala de [-1:+1], de acordo com o perfil socioeconômico dos alunos do país. Valores próximos à -1 representa um baixo nível de desenvolvimento econômico, social e cultural, valores próximos à +1 indicam alto nível para esse indicador. 
Esta sessão pretendeu a apresentar a origem e a descrição dos elementos que serão utilizados para analisar a qualidade da educação relacionada ao contexto econômicos dos setes países da América Latina, cuja principais intervenções no campo da educação serão apresentadas na sequência.

\section{Políticas Públicas de Educação e Contexto Socioeconômico dos Países Selecionados}

\section{Argentina}

Apesar das repetidas crises econômicas e das incertezas políticas enfrentadas pelo governo argentino nas últimas décadas (1990 - 2015), os dados do sistema educacional informam um avanço em termos de qualidade e abrangência. Na esfera legal, os principais marcos dos últimos anos são: Lei 25.864, de 2003, conhecida como Lei dos 180 dias de aula; Lei 26.058, de 2005 (Lei de Educação Técnico-Profissional); Lei 26.075, também de 2005 (Lei de Financiamento Educativo); Lei 26.206, de 2006 (Lei de Educação Nacional).

Todavia, é importante ressaltar que essas novas leis apenas aperfeiçoam o sistema educacional argentino, cujas bases foram estabelecidas desde 1884, com a Lei 1.420 (Lei de Educação Comum), que determinou o caráter obrigatório, estatal e laico da educação (VARGAS e PERDIGÃO, 2014). Embora, as bases sejam do século XIX, somente em 1993 foi introduzida a noção de educação básica no sistema educacional argentino, com a sanção da Lei Federal de Educação, unindo os níveis de educação primária e secundária no conceito de Educação Geral Básica (FELDFEBER e GLUZ, 2014).

Atualmente, a educação básica argentina, considerada em seu conjunto (níveis inicial, primário e secundário), apresenta diferentes modalidades no intuito de atender necessidades e situações específicas, a saber: técnico-profissional; artística; especial; permanente de jovens e adultos; rural; intercultural bilíngue; privação da liberdade; domiciliar e hospitalar. Além disso, há divisões por áreas no nível secundário, no chamado ciclo orientado, que reúne temas como:
Arte, Comunicação, Ciências Naturais, Economia e Administração, Educação Física, Línguas, Ciências Sociais e Turismo (VARGAS e PERDIGÃO, 2014).

No intuito de fornecer uma melhor compreensão da complexidade do sistema educacional argentino, será apresentado a seguir um conjunto de estatísticas sobre a educação no país. Para tal levantamento, foram utilizados bancos de dados e relatórios da Organização das Nações Unidas para a Educação, a Ciência e a Cultura (UNESCO). A Tabela 4 apresenta os principais indicadores socioeconômicos do país.

Tabela 4 . Indicadores sociais e demográficos da Argentina (2015)

\begin{tabular}{|l|c|}
\hline \multicolumn{1}{|c|}{ Indicador } & Valores \\
\hline População total & 43.417 .000 \\
\hline Crescimento anual da população (\%) & $1,0 \%$ \\
\hline População rural (\% da população total) & $8,0 \%$ \\
\hline $\begin{array}{l}\text { Taxa de mortalidade infantil (por 1000 } \\
\text { nascidos vivos) }\end{array}$ & 11 \\
\hline Expectativa de vida (anos) & 76 anos \\
\hline $\begin{array}{l}\text { Escolaridade média (em anos) para } \\
\text { população maior de 25 anos }\end{array}$ & 9,3 anos \\
\hline $\begin{array}{l}\text { Taxa de alfabetização - 15-24 anos (\% } \\
\text { da população) }\end{array}$ & $99,30 \%$ \\
\hline $\begin{array}{l}\text { Taxa de alfabetização - 15 anos ou } \\
\text { mais (\% da população) }\end{array}$ & $98,09 \%$ \\
\hline $\begin{array}{l}\text { Taxa de alfabetização - } 65 \text { anos ou } \\
\text { mais (\% da população) }\end{array}$ & $95,09 \%$ \\
\hline
\end{tabular}

Fonte: Unesco Institute for Statistics (2015)

No que se refere aos níveis de ensino, o sistema educacional argentino apresenta atualmente a configuração descrita na Tabela 5 , a seguir. 
Tabela 5 . Evolução das matrículas na Argentina por nível de ensino (2000 - 2014)

\begin{tabular}{|l|c|c|c|c|c|c|}
\hline \multicolumn{1}{|c|}{ Indicador } & $\mathbf{2 0 0 0}$ & $\mathbf{2 0 0 3}$ & $\mathbf{2 0 0 6}$ & $\mathbf{2 0 0 9}$ & $\mathbf{2 0 1 2}$ & $\mathbf{2 0 1 4}$ \\
\hline Matriculas pré-primário & 1.256 .491 & 1.266 .292 & 1.342 .505 & 1.462 .363 & 1.527 .075 & 1.597 .990 \\
\hline Taxa líquida pré-primário & $59,04 \%$ & $60,53 \%$ & $62,84 \%$ & $66,39 \%$ & $69,42 \%$ & $72,47 \%$ \\
\hline Matrículas primário & 4.900 .956 & 4.885 .664 & 4.928 .319 & 4.961 .821 & 4.871 .157 & 4.780 .105 \\
\hline Taxa líquida primário & $99,12 \%$ & $98,99 \%$ & $98,80 \%$ & $99,02 \%$ & $98,97 \%$ & $99,35 \%$ \\
\hline Matriculas secundário & 3.829 .421 & 3.902 .011 & 3.872 .929 & 4.106 .048 & 4.346 .391 & 4.450 .741 \\
\hline Taxa líquida secundário & $78,97 \%$ & $79,17 \%$ & $79,11 \%$ & $82,41 \%$ & $87,32 \%$ & $88,25 \%$ \\
\hline
\end{tabular}

Fonte: Compilado a partir da base de dados do Unesco Institute for Statistics (2015)

A Tabela 5 apresenta o número de matrículas de cada nível de ensino e a sua respectiva taxa líquida, que considera para seu cálculo o número de matriculados que são da faixa etária esperada para um determinado nível de ensino. A saber, de acordo com a legislação do país, o período de ensino obrigatório se inicia a partir dos quatro anos de idade, embora o nível pré-primário considere crianças a partir de três anos. Deste modo, considera-se regularmente inscrito no pré-primário os estudantes compreendidos na faixa etária de 3 até 5 , no primário aqueles que possuem entre 6 e 12 anos e no secundário os que possuem de 12 a 17 anos. Para todas as modalidades de ensino observou-se uma significativa melhora nas taxas de matrícula, quando considerados a educação primária, aquela cujo objetivo consiste no processo de alfabetização, observa-se que praticamente toda a população argentina daquela respectiva faixa etária se encontra matriculada regularmente.

Outro ponto a ser considerado é a evolução do gasto público com educação. A Tabela 6, a seguir, apresenta o gasto governamental em três diferentes perspectivas, a saber: em comparação com o PIB; em comparação com o total do gasto público; de acordo com cada um dos níveis de ensino.

Tabela 6 . Resumo do gasto público com educação na Argentina (2000 - 2014)

\begin{tabular}{|l|c|c|c|c|c|c|}
\hline Indicador & $\mathbf{2 0 0 0}$ & $\mathbf{2 0 0 3}$ & $\mathbf{2 0 0 6}$ & $\mathbf{2 0 0 9}$ & $\mathbf{2 0 1 2}$ & $\mathbf{2 0 1 4}$ \\
\hline $\begin{array}{l}\text { Gasto governamental em educação em porcentagem } \\
\text { do PIB }\end{array}$ & $4,58 \%$ & $3,53 \%$ & $4,11 \%$ & $5,52 \%$ & $5,32 \%$ & $5,33 \%$ \\
\hline $\begin{array}{l}\text { Gasto com educação como percentual do gasto total } \\
\text { do governo }\end{array}$ & $16,23 \%$ & $14,36 \%$ & $16,38 \%$ & $16,95 \%$ & $15,34 \%$ & $14,72 \%$ \\
\hline $\begin{array}{l}\text { Gasto com ensino pré-primário como percentual do } \\
\text { gasto governamental com educação }\end{array}$ & $07,76 \%$ & $08,54 \%$ & $07,18 \%$ & $07,57 \%$ & $07,82 \%$ & $8,06 \%$ \\
\hline $\begin{array}{l}\text { Gasto com ensino primário como percentual do } \\
\text { gasto governamental com educação }\end{array}$ & $35,69 \%$ & $38,01 \%$ & $35,04 \%$ & $32,80 \%$ & $31,80 \%$ & $30,06 \%$ \\
\hline $\begin{array}{l}\text { Gasto com ensino secundário como percentual do } \\
\text { gasto governamental com educação }\end{array}$ & $35,70 \%$ & $37,26 \%$ & $40,02 \%$ & $40,7 \% 7$ & $40,44 \%$ & $41,48 \%$ \\
\hline
\end{tabular}

* Dados de 2015 ainda não foram divulgados.

Fonte: Compilado a partir da base de dados do Unesco Institute for Statistics (2015)

Nota-se que, apesar de algumas oscilações, o gasto governamental apresentou um pequeno crescimento no intervalo de 2000 a 2014. No entanto, o percentual do gasto com educação em comparação com o gasto total do governo sofreu uma leve queda.

Outro fator a ser destacado é que, em termos de gasto público, parece ter ocorrido uma mudança de prioridade, uma vez que o gasto com ensino primário sofreu uma redução de 35,69\% em 2000 para 30,06\% em 2014; enquanto o gasto com o ensino secundário passou de 35,7\% para 41,48\% no mesmo período. Redução do número de estudante no ensino primário também pode explicar a redução observada. Isso pode ser parcialmente 
explicado pelos dados apresentados na Tabela 5, que informam que houve uma redução do número absoluto de matrículas no nível primário, enquanto as matrículas do pré-primário e secundário cresceram. Além disso, a taxa líquida de matrícula no ensino primário era de $99 \%$ desde 2000. Já o nível pré-primário, com taxa 59,04\%, e o nível secundário, com taxa 78,97\%, necessitavam de investimento maior para ampliação do alcance.

\section{Brasil}

A educação no Brasil esteve por muito tempo restrita as classes mais altas. Somente em 1824, com a Constituição do Império, tal realidade começou a mudar, com a introdução de uma estrutura educacional gratuita aos cidadãos. Todavia, ainda havia restrições, pois, o conceito de cidadão excluía determinada parcela da população (SANTOS, 2016). Com o advento da República, em 1889, e da nova Constituição, de 1891, o Estado brasileiro se torna uma federação, o que influencia a gestão educacional, pois os entes da federação passam a gozar de autonomia e poder decisório. No entanto, foi somente na década de 1980 que esta descentralização se materializou com mais força a nível municipal, com a proposta de adequar os currículos às realidades regionais e locais (SANTOS, 2016).

Somente a partir das duas últimas décadas do século XX, o país obteve avanços importantes, conforme destaque do Relatório Educação para Todos, da UNESCO: obrigatoriedade da matrícula das crianças de quatro e cinco anos de idade na pré-escola; quase universalização do ensino fundamental; redução significativa das taxas de analfabetismo; e aumento do financiamento da educação.

Atualmente, o sistema de ensino brasileiro é organizado em três etapas, são elas: Educação Infantil; Ensino Fundamental; e Ensino Médio. Sendo que o Ensino Fundamental é dividido em duas partes, Ciclo I, que vai do $1^{\circ}$ ao $5^{\circ}$ ano, e Ciclo II, que vai do $6^{\circ}$ ao $9^{\circ}$ ano. Observa-se também a descentralização da oferta do ensino brasileiro, que é compartilhada entre a união estados e municípios.

De modo a contextualizar a realidade brasileira, são apresentados a seguir alguns indicadores socioeconômicos e educacionais na Tabela 7.

Tabela 7 . Indicadores sociais e demográficos do Brasil 2015

\begin{tabular}{|l|c|}
\hline \multicolumn{1}{|c|}{ Indicador } & Valores \\
\hline População total & 207.848 .000 \\
\hline Crescimento anual da população (\%) & $0,9 \%$ \\
\hline População rural (\% da população total) & $14 \%$ \\
\hline Taxa de mortalidade infantil (por 1000 nascidos vivos) & 15 \\
\hline Expectativa de vida (anos) & 74 anos \\
\hline Escolaridade média (em anos) para população maior de 25 anos & 7,4 anos \\
\hline Taxa de alfabetização - 15-24 anos (\% da população) & $98,93 \%$ \\
\hline Taxa de alfabetização - 15 anos ou mais (\% da população) & $92,59 \%$ \\
\hline Taxa de alfabetização - 65 anos ou mais (\% da população) & $74,2 \%$ \\
\hline
\end{tabular}

Fonte: Unesco Institute for Statistics (2015)

O país é o mais populoso dentre os analisados, daí a necessidade de descentralização ocorrida em termos de competência da oferta de ensino. Quanto ao número de matrículas, observa-se que há poucos registros oficiais em relação ao ensino pré-primário, que só passou a receber maior atenção das autoridades brasileiras nos últimos anos, com a regulamentação do Sistema de avaliação da educação básica (Saeb) em 2005 pela Saeb Portaria Ministerial n ${ }^{\circ}$ 931/2005. Os dados oficiais estão contidos na Tabela 8. 
Tabela 8 . Evolução das matrículas no Brasil por nível de ensino (2000 - 2015)

\begin{tabular}{|l|c|c|c|c|c|c|}
\hline \multicolumn{1}{|c|}{ Indicador } & $\mathbf{2 0 0 0}$ & $\mathbf{2 0 0 3}$ & $\mathbf{2 0 0 6}$ & $\mathbf{2 0 0 9}$ & $\mathbf{2 0 1 2}$ & $\mathbf{2 0 1 5}$ \\
\hline Número de matrículas - pré-primário & - & - & - & 4.900 .441 & 4.765 .943 & 4.923 .158 \\
\hline Taxa líquida de matrículas - pré-primário & - & - & - & - & - & $81,98 \%$ \\
\hline Número de matrículas - primário & 20.211 .506 & 18.919 .122 & - & 17.451 .886 & 16.134 .889 & 17.035 .929 \\
\hline Taxa líquida de matrículas - primário & - & $93,18 \%$ & - & $95,53 \%$ & $95,05 \%$ & $92,70 \%$ \\
\hline Número de matrículas - secundário & - & 24.592 .569 & - & 23.616 .942 & 23.134 .072 & 23.501 .784 \\
\hline Taxa líquida de matrículas - secundário & - & - & - & $78,80 \%$ & $78,53 \%$ & $81,35 \%$ \\
\hline
\end{tabular}

Fonte: Unesco Institute for Statistics (2015)

O pré-primário no Brasil compreende a educação básica dos anos iniciais e contempla os estudantes da faixa etária de três a cinco anos, já o primário consiste nos anos iniciais da modalidade de ensino chamada de Ensino Fundamental, para os estudantes de seis a dez anos. O secundário segundo as normas brasileiras equivale à junção do segundo segmento do Ensino Fundamental com as três séries do Ensino Médio Regular, para os alunos na faixa etária de 11 a 17 anos.

A destinação de verbas para a educação sofreu ampliações significativas nos últimos anos, tanto em relação ao PIB como em relação ao total do gasto público, conforme demonstrado na Tabela 9.

Tabela 9 . Resumo do gasto público com educação no Brasil (2000 - 2013)

\begin{tabular}{|l|c|c|c|c|c|c|}
\hline \multicolumn{1}{|c|}{ Indicador } & $\mathbf{2 0 0 0}$ & $\mathbf{2 0 0 3}$ & $\mathbf{2 0 0 6}$ & $\mathbf{2 0 0 9}$ & $\mathbf{2 0 1 2}$ & $\mathbf{2 0 1 3}$ \\
\hline $\begin{array}{l}\text { Gasto governamental em educação em porcentagem do } \\
\text { PIB }\end{array}$ & $3,95 \%$ & - & $4,87 \%$ & $5,47 \%$ & $5,80 \%$ & $5,99 \%$ \\
\hline $\begin{array}{l}\text { Gasto com educação como percentual do gasto total do } \\
\text { governo }\end{array}$ & $11,45 \%$ & - & $12,42 \%$ & $14,72 \%$ & $15,55 \%$ & $15,97 \%$ \\
\hline $\begin{array}{l}\text { Gasto com ensino pré-primário como percentual do } \\
\text { gasto governamental com educação }\end{array}$ & $8,60 \%$ & - & $7,52 \%$ & $7,02 \%$ & $10,12 \%$ & $10,50 \%$ \\
\hline $\begin{array}{l}\text { Gasto com ensino primário como percentual do gasto } \\
\text { governamental com educação }\end{array}$ & $30,88 \%$ & - & $32,02 \%$ & $32,38 \%$ & $28,89 \%$ & $27,41 \%$ \\
\hline $\begin{array}{l}\text { Gasto com ensino secundário como percentual do gasto } \\
\text { governamental com educação }\end{array}$ & $38,44 \%$ & - & $43,79 \%$ & $44,61 \%$ & $44,62 \%$ & $43,93 \%$ \\
\hline
\end{tabular}

Fonte: Unesco Institute for Statistics (2015)

No caso brasileiro, nota-se que praticamente todos os indicadores relacionados ao gasto público com educação apresentaram elevação. A única exceção foi o gasto governamental com ensino primário, que passou de 30,88\%, em 2000, para 27,41\%, em 2013.

Embora o investimento tenha aumentado, vale destacar que, dentre os sete países analisados, o Brasil possui o maior percentual de repetentes no nível primário, a segunda pior taxa de transição para o nível secundário e a menor média de escolaridade. Embora seja preciso considerar que alguns países adotam políticas de aprovação automática, esses números são preocupantes. Outro aspecto negativo do desempenho brasileiro é que o país lidera a taxa de analfabetismo na população adulta. Outro fator que chama atenção é que o país é um dos que apresenta maiores lacunas na disponibilização e organização dos dados referentes aos indicadores que foram apresentados aqui. 


\section{Chile}

As bases da educação chilena foram instituídas pela Lei de Instrução Primária, criada em 1860 e posteriormente reformulada em 1920, com a introdução da obrigatoriedade da educação básica para todas as crianças. Contudo, a universalização do ensino foi atingida somente na década de 1960 (MELLO, 2014). O sistema chileno, por meio de sua Lei Geral da Educação (LGE), de 2009, valoriza a liberdade dos estabelecimentos educacionais. O intuito é que a competição entre escolas e métodos contribua para ganhos de eficiência e desempenho, o que de alguma forma trouxe resultados positivos, porém ainda há o desafio da desigualdade a ser superado, para que todos partam de um grau mínimo de condições (MELLO, 2014).

Entre os objetivos da educação básica chilena está a potencialização da aprendizagem dos alunos nas disciplinas de Linguagem e Comunicação, Matemáticas, Ciências Naturais e Ciências Sociais (História, Geografia e Ciências Sociais). O ensino obrigatório no Chile, de acordo com a legislação, tem início a partir dos 5 anos, apesar do ensino pré-primário considerar o terceiro ano de vida como ponto de partida. Além disso, de acordo com a Unesco, o ensino primário chileno vai dos seis aos 11 anos e o secundário dos 12 aos 17.

A tabela 10 apresenta os principais dados socioeconômicos do Chile para o ano de 2015

Tabela 10 . Indicadores sociais e demográficos do Chile (2015)

\begin{tabular}{|l|c|}
\hline \multicolumn{1}{|c|}{ Indicadores } & Valores \\
\hline População total & 17.948 .000 \\
\hline Crescimento anual da população (\%) & $1,0 \%$ \\
\hline População rural (\% da população total) & $10,0 \%$ \\
\hline Taxa de mortalidade infantil (por 1000 nascidos vivos) & 7 \\
\hline Expectativa de vida (anos) & 81 anos \\
\hline Escolaridade média (em anos) para população maior de 25 anos & 10,04 anos \\
\hline Taxa de alfabetização - 15-24 anos (\% da população) & $99,15 \%$ \\
\hline Taxa de alfabetização - 15 anos ou mais (\% da população) & $96,63 \%$ \\
\hline Taxa de alfabetização - 65 anos ou mais (\% da população) & $89,74 \%$ \\
\hline
\end{tabular}

Fonte: Unesco Institute for Statistics (2015)

Quanto aos indicadores educacionais, o Chile apresenta a população com maior escolaridade média e é o segundo na taxa de transição do nível primário para o nível secundário. Além disso, apresenta uma das taxas mais altas de alfabetização de jovens entre os países da América Latina. A Tabela 11 apresenta os valores com a evolução de matrículas para o período analisado.

Tabela 11 . Evolução das matrículas no Chile por nível de ensino (2000 - 2015)

\begin{tabular}{|l|c|c|c|c|c|c|}
\hline \multicolumn{1}{|c|}{ Indicador } & $\mathbf{2 0 0 0}$ & $\mathbf{2 0 0 3}$ & $\mathbf{2 0 0 6}$ & $\mathbf{2 0 0 9}$ & $\mathbf{2 0 1 2}$ & $\mathbf{2 0 1 5}$ \\
\hline Número de matrículas - pré-primário & 450.978 & 392.995 & 401.899 & 413.895 & 555.046 & 616.237 \\
\hline Taxa líquida de matrículas - pré-primário & - & - & - & $67,87 \%$ & $86,58 \%$ & $80,76 \%$ \\
\hline Número de matrículas - primário & 1.798 .515 & 1.713 .538 & 1.694 .765 & 1.611 .682 & 1.503 .898 & 1.477 .538 \\
\hline Taxa líquida de matrículas - primário & - & - & - & $94,49 \%$ & $93,12 \%$ & $94,32 \%$ \\
\hline Número de matrículas - secundário & 1.391 .283 & 1.557 .120 & 1.633 .868 & 1.528 .200 & 1.443 .554 & 1.546 .323 \\
\hline Taxa líquida de matrículas - secundário & - & - & - & $88,47 \%$ & $86,41 \%$ & $87,97 \%$ \\
\hline
\end{tabular}

Fonte: Compilado da base de dados do Unesco Institute for Statistics (2015)

Os gastos públicos do Chile com educação são informados na Tabela 12, a seguir. 
Tabela 12 . Resumo do gasto público com educação no Chile (2000 - 2015)

\begin{tabular}{|l|c|c|c|c|c|c|}
\hline \multicolumn{1}{|c|}{ Indicador } & $\mathbf{2 0 0 0}$ & $\mathbf{2 0 0 3}$ & $\mathbf{2 0 0 6}$ & $\mathbf{2 0 0 9}$ & $\mathbf{2 0 1 2}$ & $\mathbf{2 0 1 5}$ \\
\hline Gasto governamental em educação em porcentagem do PIB & $3,71 \%$ & $3,85 \%$ & $3,02 \%$ & $4,24 \%$ & $4,58 \%$ & $4,92 \%$ \\
\hline $\begin{array}{l}\text { Gasto com educação como percentual do gasto total do } \\
\text { governo }\end{array}$ & $16,40 \%$ & $17,60 \%$ & $16,20 \%$ & $16,99 \%$ & $19,64 \%$ & $18,90 \%$ \\
\hline $\begin{array}{l}\text { Gasto com ensino pré-primário como percentual do gasto } \\
\text { governamental com educação }\end{array}$ & $8,18 \%$ & $8,67 \%$ & $10,69 \%$ & $12,78 \%$ & $14,02 \%$ & $13,18 \%$ \\
\hline $\begin{array}{l}\text { Gasto com ensino primário como percentual do gasto } \\
\text { governamental com educação }\end{array}$ & $43,02 \%$ & $39,79 \%$ & $35,89 \%$ & $36,39 \%$ & $32,07 \%$ & $25,61 \%$ \\
\hline $\begin{array}{l}\text { Gasto com ensino secundário como percentual do gasto } \\
\text { governamental com educação }\end{array}$ & $34,27 \%$ & $38,38 \%$ & $38,60 \%$ & $35,23 \%$ & $32,79 \%$ & $29,37 \%$ \\
\hline
\end{tabular}

Fonte: Compilado da base de dados do Unesco Institute for Statistics (2015)

O resumo dos gastos mostra que o dispêndio de recursos governamentais com educação tanto em comparação com o PIB como em comparação com o gasto governamental total cresceram expressivamente desde o final da década de 1990. Por outro lado, o gasto proporcional com o ensino primário e secundário diminuiu significativamente nos últimos anos. O ensino primário registrou queda de quase $20 \%$ e o ensino secundário cerca de 5\%. Parte da explicação para esses números está no fechamento de centenas de escolas públicas chilenas e do avanço do sistema privado, dado que o Chile tem enfrentado nos últimos anos o fechamento de escolas públicas e um crescimento significativo do número de estabelecimentos privados.

\section{Colômbia}

A educação pública obrigatória colombiana foi instituída na década de 1920. Todavia, a escolarização primária começou a se aproximar da universalização apenas recentemente. Além disso, apesar dos avanços na educação primária, a educação secundária ainda sofre com baixas taxas de conclusão, desigualdade no acesso e baixa qualidade do ensino (GONÇALVES e PARRA, 2014).

Vale destacar que o Ministério da Educação colombiano, ente encarregado pela coordenação do setor no país, delega às secretarias de educação a gestão e organização das regiões. Os níveis de educação estão divididos em: pré-escolar, com duração de três anos, ou seja, do terceiro ao quinto ano de vida; educação básica, com duração de nove anos e dividida em dois ciclos; e educação média, com duração de dois anos. Já a classificação dos níveis de ensino segundo a Unesco, considera o ensino pré-escolar colombiano como o pré-primário; o primeiro ciclo da educação básica como o ensino primário; e o segundo ciclo da educação básica juntamente com a educação média como o nível de ensino secundário. Dos sete países analisados, a Colômbia é o que apresenta o menor período de ensino obrigatório. Apesar da distribuição dos níveis de ensino descritos acima, o ensino obrigatório ocorre dos cinco aos 14 anos de idade.

A Tabela 13 apresenta os dados sociais e demográficos da Colômbia de 2015.

Tabela 13 . Indicadores sociais e demográficos da Colômbia (2015)

\begin{tabular}{|l|c|}
\hline \multicolumn{1}{|c|}{ Indicadores } & Valores \\
\hline População total & 48.229 .000 \\
\hline Crescimento anual da população (\%) & $0,9 \%$ \\
\hline População rural (\% da população total) & $24,0 \%$ \\
\hline Taxa de mortalidade infantil (por 1000 nascidos vivos) & 14 \\
\hline Expectativa de vida (anos) & 74 anos \\
\hline Escolaridade média (em anos) para população maior de 25 anos & $8,06 \%$ \\
\hline Taxa de alfabetização - 15-24 anos (\% da população) & $98,66 \%$ \\
\hline
\end{tabular}




\begin{tabular}{|l|l|}
\hline Taxa de alfabetização - 15 anos ou mais (\% da população) & $94,58 \%$ \\
\hline Taxa de alfabetização - 65 anos ou mais (\% da população) & $81,29 \%$ \\
\hline
\end{tabular}

Fonte: Unesco Institute for Statistics (2015)

Os indicadores mostram que a Colômbia apresenta a segunda pior média de escolaridade, estando a frente apenas do Brasil. Por outro lado, a taxa de alfabetização é similar a dos demais países da América Latina.

Tabela 14 . Evolução das matrículas na Colômbia por nível de ensino (2000 - 2015)

\begin{tabular}{|l|c|c|c|c|c|c|}
\hline \multicolumn{1}{|c|}{ Indicador } & $\mathbf{2 0 0 0}$ & $\mathbf{2 0 0 3}$ & $\mathbf{2 0 0 6}$ & $\mathbf{2 0 0 9}$ & $\mathbf{2 0 1 2}$ & $\mathbf{2 0 1 5}$ \\
\hline Número de matrículas - pré-primário & 1.070 .482 & - & 1.105 .726 & 1.371 .863 & - & 1.922 .637 \\
\hline Taxa líquida de matrículas - pré-primário & $37,74 \%$ & - & $38,63 \%$ & $50,63 \%$ & - & $80,97 \%$ \\
\hline Número de matrículas - primário & 5.221 .018 & - & 5.296 .190 & 5.299 .258 & 4.742 .456 & 4.479 .218 \\
\hline Taxa líquida de matrículas - primário & $94,64 \%$ & - & $92,76 \%$ & $93,29 \%$ & $91,47 \%$ & $90,60 \%$ \\
\hline Número de matrículas - secundário & 3.568 .889 & - & 4.509 .406 & 4.992 .062 & 4.903 .462 & 4.793 .963 \\
\hline Taxa líquida de matrículas - secundário & - & - & $68,90 \%$ & $77,22 \%$ & $79,19 \%$ & $78,29 \%$ \\
\hline
\end{tabular}

Fonte: Compilado da base de dados do Unesco Institute for Statistics (2015)

Quanto ao gasto público com educação, ao longo dos últimos anos, observa-se pouca diferença em relação a percentuais do PIB, porém é possível notar um incremento do investimento na área em comparação com o gasto público total.

Tabela 15 . Resumo do gasto público com educação na Colômbia (2000 - 2015)

\begin{tabular}{|l|c|c|c|c|c|c|}
\hline \multicolumn{1}{|c|}{ Indicador } & $\mathbf{2 0 0 0}$ & $\mathbf{2 0 0 3}$ & $\mathbf{2 0 0 6}$ & $\mathbf{2 0 0 9}$ & $\mathbf{2 0 1 2}$ & $\mathbf{2 0 1 5}$ \\
\hline $\begin{array}{l}\text { Gasto governamental em educação em porcentagem } \\
\text { do PIB }\end{array}$ & $3,50 \%$ & $4,33 \%$ & $3,89 \%$ & $4,74 \%$ & $4,39 \%$ & $4,49 \%$ \\
\hline $\begin{array}{l}\text { Gasto com educação como percentual do gasto total } \\
\text { do governo }\end{array}$ & $13,29 \%$ & $15,54 \%$ & $13,77 \%$ & $16,08 \%$ & $15,51 \%$ & $15,05 \%$ \\
\hline $\begin{array}{l}\text { Gasto com ensino pré-primário como percentual do } \\
\text { gasto governamental com educação }\end{array}$ & $2,45 \%$ & - & - & $5,70 \%$ & $5,96 \%$ & $5,89 \%$ \\
\hline $\begin{array}{l}\text { Gasto com ensino primário como percentual do } \\
\text { gasto governamental com educação }\end{array}$ & $44,56 \%$ & - & - & $38,41 \%$ & $34,96 \%$ & $36,72 \%$ \\
\hline $\begin{array}{l}\text { Gasto com ensino secundário como percentual do } \\
\text { gasto governamental com educação }\end{array}$ & $33,07 \%$ & - & - & $35,01 \%$ & $35,70 \%$ & $35,41 \%$ \\
\hline
\end{tabular}

Fonte: Compilado da base de dados do Unesco Institute for Statistics (2015)

A análise dos indicadores colombianos evidencia que apesar de alguns avanços na área educacional, ainda há muito trabalho a ser feito. Por exemplo, a Colômbia apresenta baixo grau de repetência e a melhor taxa de transição do ensino primário para o secundário. No entanto, o que aparentemente parece indicar um bom desempenho pode ser melhor explicado pelas políticas de aprovação automática.

Além disso, os números mostram um avanço na cobertura educacional, porém algo que foi mais contundente no nível primário, pois no nível secundário a taxa de cobertura ainda é insatisfatória, principalmente se for feito um recorte da chamada educação média, que corresponde aos dois anos finais do nível secundário. 


\section{México}

A educação básica, gratuita e obrigatória foi estabelecida no México pelos artigos $3^{\circ}$ e $31^{\circ}$ da Constituição de 1917. Tal mudança constitucional influenciou a criação da Secretaria de Educação Pública (SEP), em 1921, que até hoje administra e supervisiona o sistema educacional, centralizando a elaboração, avaliação e promoção das políticas públicas de educação (LOPES e CHUC, 2014).

O sistema educacional mexicano está dividido em: a) educação inicial, ofertado para crianças até os seis anos; b) educação básica, que atende crianças de seis a 14 anos; c) ensino médio, equivalente ao brasileiro. Na educação básica as disciplinas envolvem áreas como: Espanhol, Matemática, Exploração da Natureza e d a Sociedade, Formação Cívica e Ética, Ciências Naturais, Geografia, História, Inglês, Aprender a Aprender, Disciplina Estatal, Educação Física, Educação Artística. Já no Ensino Médio os jovens mexicanos têm acesso a disciplinas como: Matemática, Química, Informática, Ética, Orientação Educativa, Física, História, Psicologia, Biologia, Literatura, Etimologias Greco-Latinas.

No entanto, a classificação da Unesco chama a educação inicial mexicana de educação pré-primária; e segmenta a educação básica, parte dela será classificada dentro do nível primário, crianças de seis a 11 anos, e a outra parte será somada aos anos do ensino médio para formar o nível secundário, composto por crianças de 12 a 17 anos.

A Tabela 16, 17 e 18 trazem dados socioeconômicos mexicanos para auxiliar a contextualização dos demais dados levantados sobre a educação do país.

Tabela 16 . Indicadores sociais e demográficos do México (2015)

\begin{tabular}{|l|c|}
\hline \multicolumn{1}{|c|}{ Indicadores } & Valores \\
\hline População total & 127.017 .000 \\
\hline Crescimento anual da população (\%) & $1,3 \%$ \\
\hline População rural (\% da população total) & $21,0 \%$ \\
\hline Taxa de mortalidade infantil (por 1000 nascidos vivos) & 11 \\
\hline Expectativa de vida (anos) & 77 anos \\
\hline Escolaridade média (em anos) para população maior de 25 anos & 8,6 anos \\
\hline Taxa de alfabetização - 15-24 anos (\% da população) & $98,74 \%$ \\
\hline Taxa de alfabetização - 15 anos ou mais (\% da população) & $94,55 \%$ \\
\hline
\end{tabular}

Fonte: Unesco Institute for Statistics (2015)

Tabela 17 . Evolução das matrículas no México por nível de ensino $(2000$ - 2015)

\begin{tabular}{|l|c|c|c|c|c|c|}
\hline \multicolumn{1}{|c|}{ Indicador } & $\mathbf{2 0 0 0}$ & $\mathbf{2 0 0 3}$ & $\mathbf{2 0 0 6}$ & $\mathbf{2 0 0 9}$ & $\mathbf{2 0 1 2}$ & $\mathbf{2 0 1 4}$ \\
\hline $\begin{array}{l}\text { Número de matrículas - pré- } \\
\text { primário }\end{array}$ & 3.393 .741 & 3.635 .903 & 4.463 .473 & 4.645 .464 & 4.716 .545 & 4.797 .728 \\
\hline $\begin{array}{l}\text { Taxa líquida de matrículas - pré- } \\
\text { primário }\end{array}$ & $63,51 \%$ & $65,49 \%$ & $80,61 \%$ & $81,58 \%$ & $81,72 \%$ & $68,72 \%$ \\
\hline Número de matrículas - primário & 14.765 .603 & 14.857 .191 & 14.595 .195 & 14.861 .232 & 14.956 .982 & 14.627 .368 \\
\hline $\begin{array}{l}\text { Taxa líquida de matrículas - } \\
\text { primário }\end{array}$ & $96,44 \%$ & $96,39 \%$ & $93,55 \%$ & $93,92 \%$ & $96,00 \%$ & $95,06 \%$ \\
\hline $\begin{array}{l}\text { Número de matrículas - } \\
\text { secundário }\end{array}$ & 9.094 .103 & 10.188 .185 & 10.883 .455 & 11.474 .843 & 12.139 .246 & 12.993 .322 \\
\hline $\begin{array}{l}\text { Taxa líquida de matrículas - } \\
\text { secundário }\end{array}$ & $54,64 \%$ & $61,23 \%$ & $65,28 \%$ & $66,95 \%$ & $67,41 \%$ & - \\
\hline
\end{tabular}

Fonte: Compilado da base de dados do Unesco Institute for Statistics (2015) 
A Tabela 17 a seguir apresenta alguns indicadores educacionais mexicanos. Dentre eles vale destacar a evolução da taxa de transição do ensino primário para o ensino secundário, que em 1999 era de 90,1\% e que atualmente é de quase $97 \%$.

Sobre o gasto governamental com educação no México, observa-se o incremento dos investimentos em comparação com o PIB e a redução do gasto proporcional com o ensino primário.

Tabela 18 . Resumo do gasto público com educação no México (2000 - 2014)

\begin{tabular}{|l|c|c|c|c|c|c|}
\hline \multicolumn{1}{|c|}{ Indicador } & $\mathbf{2 0 0 0}$ & $\mathbf{2 0 0 3}$ & $\mathbf{2 0 0 6}$ & $\mathbf{2 0 0 9}$ & $\mathbf{2 0 1 2}$ & $\mathbf{2 0 1 4}$ \\
\hline $\begin{array}{l}\text { Gasto governamental em educação em porcentagem do } \\
\text { PIB }\end{array}$ & $4,14 \%$ & $5,18 \%$ & $\mathbf{4}, 76 \%$ & $5,21 \%$ & $5,17 \%$ & $5,31 \%$ \\
\hline $\begin{array}{l}\text { Gasto com educação como percentual do gasto total do } \\
\text { governo }\end{array}$ & $19,78 \%$ & $22,44 \%$ & $20,75 \%$ & $18,47 \%$ & $18,67 \%$ & $19,07 \%$ \\
\hline $\begin{array}{l}\text { Gasto com ensino pré-primário como percentual do } \\
\text { gasto governamental com educação }\end{array}$ & - & $11,55 \%$ & $11,15 \%$ & $9,98 \%$ & - & - \\
\hline $\begin{array}{l}\text { Gasto com ensino primário como percentual do gasto } \\
\text { governamental com educação }\end{array}$ & $40,35 \%$ & $39,28 \%$ & $38,82 \%$ & $36,22 \%$ & 34,66 & $32,76 \%$ \\
\hline $\begin{array}{l}\text { Gasto com ensino secundário como percentual do gasto } \\
\text { governamental com educação }\end{array}$ & - & $29,18 \%$ & $29,79 \%$ & $30,25 \%$ & 31,37 & $31,98 \%$ \\
\hline
\end{tabular}

Fonte: Compilado da base de dados do Unesco Institute for Statistics (2015)

Dos indicadores verificados, um dos dados que mais chama atenção é que apesar de o país apresentar um resultado razoável no que se refere à taxa líquida de matrículas para o nível primário, o desempenho nos demais níveis, com destaque para o secundário, é preocupante. O México apresenta uma das menores taxas líquidas de matrículas no nível secundário (67,41\% em 2012), embora o gasto público para esse nível de ensino específico tenha crescido quase três pontos percentuais na última década.

\section{Peru}

Um dos pontos fundamentais da educação peruana foi a promulgação do "Reglamento de Instrucción", em 1850, conhecido como a primeira lei pública de instrução. Tal dispositivo legal abordava o funcionamento das escolas, faculdades e universidades, bem como o regime de orientações políticas educacionais no ensino público e privado (Ministerio de Educación de Perú y Organización de Estados Iberoamericanos, 1994).

Outros marcos relevantes para o estabelecimento da educação pública e obrigatória peruana foram: (i) Lei Orgânica de Educação, de 1901; e (ii) Lei no 162, de 1905. Após tais mudanças o número de escolas e alunos no país praticamente dobrou em um período de apenas três anos.

O período de ensino obrigatório no Peru é de 14 anos, com início aos três e término aos 16 anos. O sistema peruano tem como primeiro nível a educação infantil, que engloba crianças até os seis anos de idade. A partir dos seis anos, as crianças ingressam no ensino primário, que tem duração de seis anos e é dividido em três fases, cada uma com dois anos de duração. Por fim, os jovens cursam o ensino secundário, que vai até os 16 anos de idade.

Para acompanhamento do sistema de ensino, o Ministério de Educação peruano possui um diretório institucional central, que se articula com diretórios regionais, e estes dialogam com as chamadas unidades de gestão educativa locais, o que garante relativa autonomia e flexibilidade para as regiões.

As Tabelas 19, 20 e 21 a seguir, apresentam um resumo de alguns indicadores socioeconômicos do Peru para contextualização da análise. 
Tabela 19. Indicadores sociais e demográficos do Peru

\begin{tabular}{|l|c|}
\hline \multicolumn{1}{|c|}{ Indicadores } & Resultados \\
\hline População total & 31.377 .000 \\
\hline Crescimento anual da população (\%) & $1,3 \%$ \\
\hline População rural (\% da população total) & $21,0 \%$ \\
\hline Taxa de mortalidade infantil (por 1000 nascidos vivos) & 13 \\
\hline Expectativa de vida (anos) & 75 \\
\hline Escolaridade média (em anos) para população maior de 25 anos & 9,1 \\
\hline Taxa de alfabetização - 15-24 anos (\% da população) & 98,93 \\
\hline Taxa de alfabetização - 15 anos ou mais (\% da população) & 94,37 \\
\hline Taxa de alfabetização - 65 anos ou mais (\% da população) & 77,59 \\
\hline
\end{tabular}

Fonte: Unesco Institute for Statistics (2015)

Pode-se observar pelas Tabelas a seguir que, nas últimas décadas, a taxa líquida de matrículas aumentou nos níveis pré-primário e secundário, porém sofreu uma redução no nível primário.

Tabela 20 . Evolução das matrículas no Peru por nível de ensino (2000 - 2015)

\begin{tabular}{|l|c|c|c|c|c|c|}
\hline \multicolumn{1}{|c|}{ Indicador } & $\mathbf{2 0 0 0}$ & $\mathbf{2 0 0 3}$ & $\mathbf{2 0 0 6}$ & $\mathbf{2 0 0 9}$ & $\mathbf{2 0 1 3}$ & $\mathbf{2 0 1 5}$ \\
\hline Número de matrículas - pré-primário & 1.061 .307 & 1.044 .565 & 1.130 .601 & 1.352 .528 & 1.502 .590 & 1.578 .698 \\
\hline Taxa líquida de matrículas - pré-primário & $58,10 \%$ & $59,37 \%$ & $64,08 \%$ & $75,58 \%$ & $84,32 \%$ & $88,36 \%$ \\
\hline Número de matrículas - primário & 4.338 .080 & 4.200 .489 & 4.026 .316 & 3.787 .409 & 3.545 .103 & 3.513 .439 \\
\hline Taxa líquida de matrículas - primário & $97,57 \%$ & $99,54 \%$ & $96,20 \%$ & $96,15 \%$ & $93,16 \%$ & $94,08 \%$ \\
\hline Número de matrículas - secundário & 2.374 .178 & 2.347 .247 & 2.539 .939 & 2.659 .945 & 2.731 .762 & 2.681 .531 \\
\hline Taxa líquida de matrículas - secundário & $65,02 \%$ & - & $72,11 \%$ & $79,91 \%$ & $79,46 \%$ & $77,68 \%$ \\
\hline
\end{tabular}

Fonte: Compilado da base de dados do Unesco Institute for Statistics (2015)

O sistema educacional peruano apresenta resultados próximos aos da média geral dos países da América Latina, conforme Tabela 21, a seguir.

Tabela 21 . Resumo do gasto público com educação no Peru (2000 - 2015)

\begin{tabular}{|l|c|c|c|c|c|c|}
\hline \multicolumn{1}{|c|}{ Indicador } & $\mathbf{2 0 0 0}$ & $\mathbf{2 0 0 3}$ & $\mathbf{2 0 0 6}$ & $\mathbf{2 0 0 9}$ & $\mathbf{2 0 1 2}$ & $\mathbf{2 0 1 5}$ \\
\hline $\begin{array}{l}\text { Gasto governamental em educação em porcentagem do } \\
\text { PIB }\end{array}$ & $3,22 \%$ & $2,94 \%$ & $2,66 \%$ & $3,14 \%$ & $2,92 \%$ & $3,98 \%$ \\
\hline $\begin{array}{l}\text { Gasto com educação como percentual do gasto total do } \\
\text { governo }\end{array}$ & $15,25 \%$ & $14,66 \%$ & $14,04 \%$ & $14,60 \%$ & $14,37 \%$ & $17,60 \%$ \\
\hline $\begin{array}{l}\text { Gasto com ensino pré-primário como percentual do } \\
\text { gasto governamental com educação }\end{array}$ & $9,30 \%$ & $8,96 \%$ & $9,55 \%$ & $11,70 \%$ & $13,40 \%$ & $16,64 \%$ \\
\hline $\begin{array}{l}\text { Gasto com ensino primário como percentual do gasto } \\
\text { governamental com educação }\end{array}$ & $41,86 \%$ & $35,95 \%$ & $40,44 \%$ & $40,38 \%$ & $36,61 \%$ & $36,49 \%$ \\
\hline $\begin{array}{l}\text { Gasto com ensino secundário como percentual do gasto } \\
\text { governamental com educação }\end{array}$ & $28,38 \%$ & $30,31 \%$ & 35,50 & $33,48 \%$ & $31,87 \%$ & $30,78 \%$ \\
\hline
\end{tabular}

Fonte: Compilado da base de dados do Unesco Institute for Statistics (2015) 
Os gastos governamentais peruanos com educação oscilaram muito nos últimos 15 anos. Observa-se, também, o aumento expressivo dos investimentos em educação pré-primária e a redução dos gastos em educação primária. Isso tem relação com o os indicadores da taxa líquida de matrícula nos dois níveis mencionados. No nível primário houve redução da taxa de matrícula enquanto no nível pré-primário o crescimento foi acelerado. A mesma relação é observada no nível secundário, cuja taxa líquida de matrícula sofreu um aumento de mais de $12 \%$ nos últimos 15 anos, e foi acompanhado por um aumento do gasto público para esse nível de ensino de $28,38 \%$ para $30,78 \%$.

\section{Uruguai}

A educação obrigatória e gratuita foi estabelecida no Uruguai por meio do Decreto-lei de Educação Comum, de 1877. Desde então a educação no país avançou bastante. Como resultado de tais avanços o Uruguai foi considerado durante muito tempo como um dos países com os melhores índices educacionais da região (OEI, 2017). No entanto, ao longo das últimas quatro décadas, o país reduziu significativamente o ritmo de seus avanços no campo educacional, principalmente no que se refere ao aproveitamento do nível secundário de ensino (ARMAS e RETAMOSO, 2010).

O período de ensino obrigatório no Uruguai vai dos quatro aos 17 anos. O sistema é dividido em educação inicial, educação primária e educação média básica. No entanto, de acordo com a classificação da Unesco, os níveis de ensino abrangem as seguintes faixas etárias: pré-primário, de três a cinco anos (sendo que a obrigatoriedade, como já mencionado antes, ocorre somente a partir dos quatro anos); primário, de seis a 11 anos; e secundário, de 12 a 17 anos.

Segundo a lei Lei Geral de Educação (Lei N 18.437, de 2008), o Estado tem o papel de fortalecer a gestão dos centros educacionais públicos nos aspectos pedagógicos, administrativos e financeiros. Sendo assim, os chamados centros educacionais públicos recebem fundos orçamentários para a manutenção das instalações, realização de atividades acadêmicas e projetos de extensão cultural e social. Além disso, as escolas podem fazer acordos com outras instituições, com a autorização correspondente, para complementar o aporte de recursos.

As Tabelas 22, 23 e 24 a seguir, apresentam um resumo de alguns indicadores socioeconômicos do Uruguai para contextualização da análise.

Tabela 22 . Indicadores sociais e demográficos do Uruguai

\begin{tabular}{|l|c|}
\hline \multicolumn{1}{|c|}{ Indicadores } & Resultados \\
\hline População total & 3.432 .000 \\
\hline Crescimento anual da população (\%) & $0,4 \%$ \\
\hline População rural (\% da população total) & $5,0 \%$ \\
\hline Taxa de mortalidade infantil (por 1000 nascidos vivos) & 9 \\
\hline Expectativa de vida (anos) & 77 anos \\
\hline Escolaridade média (em anos) para população maior de 25 anos & 8,6 anos \\
\hline Taxa de alfabetização - 15-24 anos (\% da população) & $98,82 \%$ \\
\hline Taxa de alfabetização - 15 anos ou mais (\% da população) & $98,44 \%$ \\
\hline Taxa de alfabetização - 65 anos ou mais (\% da população) & $96,76 \%$ \\
\hline
\end{tabular}

Fonte: Unesco Institute for Statistics (2015)

Em relação aos indicadores educacionais (Tabela 22), é possível verificar a elevada taxa de alfabetização da população, incluindo a população adulta, o que demonstra um sistema sólido, pelo menos para os anos iniciais de formação. Por outro lado, o país apresenta a menor taxa de transição do ensino primário para o ensino secundário, com significativa defasagem em comparação aos demais países analisados.

Quanto à taxa de matrícula (Tabela 23), tem-se uma baixa performance do nível secundário de ensino, que dentre os países aqui analisados só fica a frente do México. 
Tabela 23 - Evolução das matrículas no Uruguai por nível de ensino $(2000$ - 2014)

\begin{tabular}{|l|c|c|c|c|c|c|}
\hline \multicolumn{1}{|c|}{ Indicador } & $\mathbf{2 0 0 0}$ & $\mathbf{2 0 0 3}$ & $\mathbf{2 0 0 6}$ & $\mathbf{2 0 0 9}$ & $\mathbf{2 0 1 2}$ & $\mathbf{2 0 1 4}$ \\
\hline Número de matrículas - pré-primário & 106.049 & 103.691 & 121.528 & 133.003 & - & 129.248 \\
\hline Taxa líquida de matrículas - pré-primário & - & - & $79,40 \%$ & $78,17 \%$ & - & $88,23 \%$ \\
\hline Número de matrículas - primário & 360.834 & 365.423 & 365.388 & 348.691 & - & 321.779 \\
\hline Taxa líquida de matrículas - primário & - & - & $99,72 \%$ & $99,12 \%$ & - & $94,22 \%$ \\
\hline Número de matrículas - secundário & 303.883 & 343.617 & 323.027 & 288.491 & - & 291.805 \\
\hline Taxa líquida de matrículas - secundário & - & - & - & $71,27 \%$ & - & $76,35 \%$ \\
\hline
\end{tabular}

Fonte: Compilado da base de dados do Unesco Institute for Statistics (2015)

Quanto ao gasto público com educação, pode se observar um salto significativo do ano 2000 para o ano de 2011, tanto em relação ao PIB quanto em relação ao total do gasto público.

Tabela 24 . Resumo do gasto público com educação no Uruguai (2000 - 2015)

\begin{tabular}{|l|c|c|c|c|c|c|c|}
\hline \multicolumn{1}{|c|}{ Indicador } & $\mathbf{2 0 0 0}$ & $\mathbf{2 0 0 3}$ & $\mathbf{2 0 0 6}$ & $\mathbf{2 0 0 7}$ & $\mathbf{2 0 0 9}$ & $\mathbf{2 0 1 1}$ & $\mathbf{2 0 1 5}$ \\
\hline Gasto governamental em educação em porcentagem do PIB & 2,42 & 2,07 & 2,88 & $\mathbf{-}$ & $\mathbf{-}$ & $\mathbf{4 , 3 6}$ & $\mathbf{-}$ \\
\hline $\begin{array}{l}\text { Gasto com educação como percentual do gasto total do } \\
\text { governo }\end{array}$ & 8,32 & 6,83 & 9,90 & $\mathbf{-}$ & $\mathbf{-}$ & 14,93 & $\mathbf{-}$ \\
\hline $\begin{array}{l}\text { Gasto com ensino pré-primário como percentual do gasto } \\
\text { governamental com educação }\end{array}$ & 9,18 & 10,50 & 8,68 & $\mathbf{-}$ & $\mathbf{-}$ & 10,16 & - \\
\hline $\begin{array}{l}\text { Gasto com ensino primário como percentual do gasto } \\
\text { governamental com educação }\end{array}$ & 32,55 & 31,10 & 33,33 & $\mathbf{-}$ & $\mathbf{-}$ & 27,88 & - \\
\hline $\begin{array}{l}\text { Gasto com ensino secundário como percentual do gasto } \\
\text { governamental com educação }\end{array}$ & 37,79 & 32,47 & 35,98 & - & - & 33,17 & - \\
\hline
\end{tabular}

Fonte: Compilado da base de dados do Unesco Institute for Statistics (2015)

Os dados de modo geral informam que as maiores dificuldades uruguaias estão no nível secundário de ensino. A baixa taxa líquida de matrículas combinada com a redução do gasto público indicam uma situação preocupante. Soma-se a isso a falta de indicadores disponíveis nas diferentes bases de dados. Há muitas lacunas nas séries históricas obtidas, o que dificulta o aprofundamento da análise do caso uruguaio.

\section{Procedimentos Metodológicos}

Em regra, nos estudos previamente apresentados observa-se que os contextos socioeconômicos são indicativos determinantes para o desempenho estudantil. Entretanto, este trabalho está interessado em investigar tanto o efeito dos fatores sociodemográficos, como as características institucionais dos países da América Latina que participam efetivamente do PISA. Isto é Argentina, Brasil, Chile, Colômbia, México, Peru e Uruguai. Para tanto, aplicou-se uma análise econométrica da relação entre desempenho dos estudantes e características socioeconômicas desses países, tendo como base os dados do PISA disponibilizados pela OCDE.

O método empregado consiste na estatística descritiva e inferencial, aplicado aos dados dos estudantes, das escolas e características dos países selecionados na última avaliação do PISA de 2000 a 2015. As informações foram coletadas do banco de dados internacional acessível no site oficial da OCDE, e posteriormente tratadas e organizadas com o auxílio do software estatístico IBM SPSS. Os procedimentos estatísticos foram aplicados de acordo com as diretrizes informadas no PIS A Data Analysis Manual SPSS®, sendo assim, todas as estatísticas apresentadas são acompanhadas dos valores de seus respectivos desvios (OECD, 2009).

Da amostra de estudantes utilizada pela OCDE para realização do PISA nos países selecionados, foram analisados a relação entre desempenho e o contexto em que eles estão inseridos. Para tanto, empregou-se o 
método estatístico de regressão linear multivariável, ajustada pelo método dos mínimos quadrados (MMQ) para se obter a curva mais apropriada para o modelo, pela soma dos quadrados das diferenças entre os valores analisados (HAIR et al., 2009) (DRAPER e SMITH, 2014). O teste permite determinar quais fatores são determinantes para o desempenho do PISA na amostra selecionada, e assim, comparar a relação entre as variáveis e resultados por país. (BUSSAB e MORETTIN, 2010) (HAIR et al., 2009).

A relação a ser determinada pelo modelo pode ser descrita conforme a Figura 1:

Figura 1. Relação a ser investigada entre as variáveis.
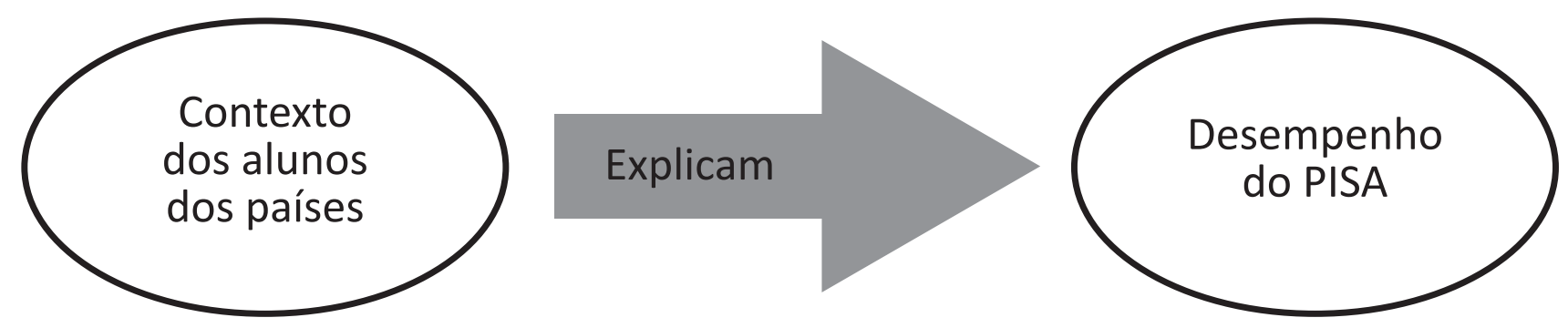

Fonte: Desenvolvido pelos autores

No modelo a ser testado, conforme ilustrado na Figura 1, o PISA é a variável dependente a ser explicada pelos fatores observados no contexto dos países analisados, isto é, pelas variáveis independentes. Assim, o teste de correlação entre as variáveis será realizado conforme a Equação 01:

$\operatorname{PISA}_{p}=\alpha_{p n}+\sum_{n}^{i=1} \gamma_{p n} E S C E e_{p n}+\epsilon_{p n}$

Para: $-\infty \leq \alpha \leq+\infty, \forall-\infty \leq \beta \leq+\infty, \forall-\infty \leq \gamma \leq+\infty, \forall-\infty \leq \delta \leq+\infty$

$-\infty \leq \alpha \leq+\infty, \forall-\infty \leq \beta \leq+\infty, \forall-\infty \leq \gamma \leq+\infty, \forall-\infty \leq \delta \leq+\infty$

Em que:

PISA $=$ Média do PISA do país $($ pPISA $p=$ Média do PISA do país $(p)$;

$\alpha_{p n}=$ Constante,que que representa a interceptação da reta com o eixo vertical

$\alpha_{p n}=$ Constante, que que representa a interceptação da reta com o eixo vertical;

$\sum_{2}^{i=1} \gamma_{i} E S C E e_{i}=$ vetor de variáveis representativas das características socieconomicas do país $(p)$

$\sum_{2}^{i=1} \gamma_{i} E S C E e_{i}=$ vetor de variáveis representativas das caracteristicas socieconomicas do país $(p)$;

$\gamma_{i}=$ expressa a sensibilidade do desempenho do país ( $p$ em relaçao as características socioeconomicas;

$\epsilon_{\text {en }}=$ Termo de perturbação do modelo, inclui todos os fatores residuais e possíveis erros de mediçãa

A variável dependente PISA assume valores relativos à média do desempenho nas três áreas de conhecimento em que os estudantes desses países foram avaliados. Para apresentação dos resultados os testes serão estratificados por disciplina avaliada, ou seja, serão aparentados analises individuais para cada uma das disciplinas - matemática, línguas e ciência. O cálculo desse valor é realizado segundo a OCDE através da média do desempenho individual dos alunos de cada país.

A variável independente a ser correlacionada com o desempenho é o perfil socioeconômico e o contexto sociodemográfico dos estudantes, medido pelo índice ESCS dos estudantes do país. O valor dessa variável é continua, e assumem valores resultantes dos índices calculados pela OCDE com base nos questionários que compõem o resultado do PISA, nos quais se coletam informações sobre os alunos e a escola avaliada. Esses questionários, que são respondidos pelos alunos e diretores, compõem a base de dados do PISA, e podem ser óbitos no site oficial da OCDE. 


\section{Resultados e Discussões}

Utilizando-se dos dados disponíveis na base de dados da OCDE, foi analisada uma amostra composta por 68.939 estudantes de 2.450 escolas distribuídas entre esses sete países, conforme apresentado na Tabela 25:

Tabela 25 . Distribuição da amostra de estudantes por países

\begin{tabular}{|l|c|c|c|}
\hline País & Língua Oficial & Estudantes & Escolas \\
\hline Argentina & Espanhol & 6.349 & 234 \\
\hline Brasil & Português & 23.141 & 841 \\
\hline Chile & Espanhol & 7.053 & 227 \\
\hline Colômbia & Espanhol & 11.795 & 372 \\
\hline México & Espanhol & 7.568 & 275 \\
\hline Peru & Espanhol & 6.971 & 281 \\
\hline Uruguai & Espanhol & 6.062 & 220 \\
\hline
\end{tabular}

Fonte: OECD (2015)

Os dados do PISA resultantes das avaliações realizadas pela OCDE, considerando a amostra descrita na Tabela 25, tiveram como propósito medir a capacidade dos estudantes de 15 anos de idade em leitura, matemática e ciência. A Tabela 26 apresenta a evolução e comparação entre os países selecionados na avaliação do PISA que mediu o desempenho médio (M) dos estudantes em leitura e seu respectivo desvio padrão (DP).

Tabela 26 . Comparação dos índices médios no domínio de leitura

\begin{tabular}{|l|c|c|c|c|c|c|c|c|}
\hline \multirow{2}{*}{ País } & \multicolumn{2}{|c|}{2006} & \multicolumn{2}{c|}{2009} & \multicolumn{2}{c|}{2012} & \multicolumn{2}{c|}{2015} \\
\cline { 2 - 9 } & M. & D.P. & M. & D.P. & M. & D.P. & M. & D.P. \\
\hline Argentina & 374 & $(7,2)$ & 398 & $(4,6)$ & 396 & $(3,7)$ & 425 & $(3,2)$ \\
\hline Brasil & 393 & $(3,7)$ & 412 & $(2,7)$ & 407 & $(2,0)$ & 407 & $(2,8)$ \\
\hline Chile & 442 & $(5,0)$ & 449 & $(3,1)$ & 441 & $(2,9)$ & 459 & $(2,6)$ \\
\hline Colômbia & 385 & $(5,1)$ & 413 & $(3,7)$ & 403 & $(3,4)$ & 425 & $(2,9)$ \\
\hline México & 410 & $(3,1)$ & 425 & $(2,0)$ & 424 & $(1,5)$ & 423 & $(2,6)$ \\
\hline Peru & $*$ & $*$ & 370 & $(4,0)$ & 384 & $(4,3)$ & 398 & $(2,9)$ \\
\hline Uruguai & 413 & $(3,4)$ & 426 & $(2,6)$ & 411 & $(3,2)$ & 437 & $(2,5)$ \\
\hline
\end{tabular}

* Dados Não disponíveis

Fonte: OCDE (2016)

Os resultados dos sete países apontam uma significativa melhora na capacidade dos seus estudantes em leitura, principalmente para Peru e Chile. O ponto em comum nos dois países é uma tendência de descentralização da proposta de ensino, concedendo mais autonomia para as escolas adaptarem as práticas para o contexto local. Todavia, os levantamentos não foram aprofundados o suficiente para indicarmos que essa seria a principal causa. Apesar da significativa melhora, o Peru ainda se encontra bastante abaixo dos demais países analisados, isto é, em média os seus estudantes ainda estão inseridos no primeiro grupo de habilidades em leitura - aquela cujos alunos apenas possuem noções essenciais de leitura e interpretação de texto.

No Brasil, Argentina, Colômbia, México e Uruguai observa-se relativa melhora nos indicares, tanto na média, quanto no desvio padrão. Isto indica que esses países vêm melhorando a qualidade de ensino e também reduzindo as desigualdades existentes entre os estudantes. Consequência das políticas públicas que estão sendo desenvolvidas nesses países. Entretanto, todos ainda estão abaixo da média dos países da OCDE, que em 2015, foi de 493 pontos. 
A Tabela 27 apresenta os dados relativos ao resultado dos países selecionados na avaliação do PISA em Matemática, a partir da avaliação do PISA de 2006.

Tabela 27 . Comparação dos índices médios no domínio da matemática

\begin{tabular}{|l|c|c|c|c|c|c|c|c|}
\hline \multirow{2}{*}{ País } & \multicolumn{2}{c|}{ 2006 } & \multicolumn{2}{c|}{ 2009 } & \multicolumn{2}{c|}{ 2012 } & \multicolumn{2}{c|}{ 2015 } \\
\cline { 2 - 10 } & Média & D.P. & Média & D.P. & Média & D.P. & Média & D.P. \\
\hline Argentina & 381 & $(6,2)$ & 388 & $(4,1)$ & 388 & $(3,5)$ & 409 & $(3,1)$ \\
\hline Brasil & 370 & $(2,9)$ & 386 & $(2,4)$ & 389 & $(1,9)$ & 377 & $(2,9)$ \\
\hline Chile & 411 & $(4,6)$ & 421 & $(3,1)$ & 423 & $(3,1)$ & 423 & $(2,5)$ \\
\hline Colômbia & 370 & $(3,8)$ & 381 & $(3,2)$ & 376 & $(2,9)$ & 390 & $(2,3)$ \\
\hline México & 406 & $(2,9)$ & 419 & $(1,8)$ & 413 & $(1,4)$ & 408 & $(2,2)$ \\
\hline Peru & $*$ & $*$ & 365 & $(4,0)$ & 368 & $(3,7)$ & 387 & $(2,7)$ \\
\hline Uruguai & 427 & $(2,6)$ & 427 & $(2,6)$ & 409 & $(2,8)$ & 418 & $(2,5)$ \\
\hline
\end{tabular}

Fonte: OCDE (2016)

* Dados Não disponíveis

Se ora o desempenho em leitura é considerado aquém no mínimo necessário pela OCDE, os resultados em matemática indicam um cenário ainda pior para os países analisados. Apesar da melhoria relativa em alguns países e a redução dos desvios, e consequentemente das desigualdades, o desempenho nesta área de conhecimento nas avaliações do PISA mostram que os estudantes desses países se encontram, em média, nos primeiros níveis de conhecimento neste campo. Isto é, apenas no Chile os estudantes conseguem interpretar literalmente certos modelos matemáticos, e para os demais, a capacidade está limitada a entender questões relativas ao seu cotidiano.

Segundo Hanushek e Woessmann (2012), o baixo desempenho nessa disciplina reduzirá a mão de obra qualificada nas áreas de engenharia e ciências exatas para as próximas cinco décadas. Nesse sentido, caberia aos estados ou importar mão de obra qualificada ou ter uma força de trabalho com níveis de produtividade inferiores aos demais países.

A Tabela 28 ilustra o desempenho dos países selecionado em ciências.

Tabela 28 . Comparação dos índices médios no domínio de ciências

\begin{tabular}{|l|c|c|c|c|c|c|c|c|}
\hline \multirow{2}{*}{ País } & \multicolumn{2}{|c|}{2006} & \multicolumn{2}{c|}{ 2009 } & \multicolumn{2}{c|}{2012} & \multicolumn{2}{c|}{2015} \\
\cline { 2 - 9 } & Média & D.P. & Média & D.P. & Média & D.P. & Média & D.P. \\
\hline Argentina & 391 & $(6,0)$ & 402 & $(4,5)$ & 405 & $(4,0)$ & 432 & $(2,9)$ \\
\hline Brasil & 387 & $(2,9)$ & 402 & $(2,5)$ & 398 & $(2,1)$ & 401 & $(2,3)$ \\
\hline Chile & 438 & $(4,3)$ & 447 & $(2,9)$ & 445 & $(2,9)$ & 447 & $(2,4)$ \\
\hline Colômbia & 387 & $(3,4)$ & 401 & $(3,7)$ & 398 & $(3,0)$ & 416 & $(2,4)$ \\
\hline México & 415 & $(2,6)$ & 419 & $(1,8)$ & 417 & $(1,3)$ & 416 & $(2,1)$ \\
\hline Peru & $*$ & $*$ & 371 & $(3,5)$ & 375 & $(3,5)$ & 397 & $(2,4)$ \\
\hline Uruguai & 427 & $(2,8)$ & 425 & $(2,7)$ & 414 & $(2,9)$ & 435 & $(2,2)$ \\
\hline
\end{tabular}

Fonte: OCDE (2016)

* Dados Não disponíveis

Do mesmo modo que nas outras disciplinas, os países analisados evoluíram também no domínio do conteúdo de ciências. A medida nessa disciplina é um pouco superior aos resultados obtidos em matemática, porém, ainda aquém da média dos países da OCDE que em 2015 foi de 493. Observa-se que o Peru e o Brasil, estão quase 100 pontos abaixo da média da OCDE, o que indica que seus estudantes apenas são capazes da aplicação do conhecimento científico em limitadas situações, as quais já estão familiarizados. Esse baixo desempenho em ciência resultará para os próximos anos em grande dificuldade desses países em desenvolver novas tecnologias 
e evoluírem tecnicamente, como novas ferramentas e patentes. Implicando assim, na redução das taxas de crescimento devido à incapacidade de competir em termos de produtividade com outros países, conforme já vem apontando Hanushek e Woessmann (2012).

Analisando em conjunto os resultados dos países nas três avaliações, nota-se, conforme as Tabelas 26, 27 e 28 que os avanços nas três áreas de conhecimento avaliadas implicaram principalmente na redução das desigualdades entre os resultados. Destaque principalmente para a Argentina, que possuía taxas de desvio bem superiores aos demais países, como foi apresentado inicialmente em 2006, de $(7,2)$ em leitura, $(6,2)$ em matemática e $(6,0)$ em ciências. Na última avaliação, em 2015, as taxas de desvio foram próximas as dos demais países do bloco, alcançado variação de (3.2), (3.1) e (2,9) em leitura, matemática e ciências, respectivamente. Esses fatores se conectam com as políticas educacionais do país. Vargas e Perdigão (2014) destacam algumas ações recentes que parecem estar diretamente relacionadas com a melhoria da qualidade do ensino, são elas: ações de reforço da leitura e escrita, fator que quando não atendido tem um impacto significativo na regularidade da trajetória escolar; produção de materiais educativos específicos para crianças com trajetórias irregulares e de alfabetização de crianças que com defasagem em leitura e escrita; planos para capacitação contínua não apenas de professores, mas também de supervisores e diretores, considerando que todos compõem o corpo daqueles que de alguma forma educam as crianças e jovens.

O Brasil em que os valores dos desvios eram nas primeiras avaliações de $(4,6),(2,9)$ e $(2,9)$, passou a ter os valores de desvio de (2.8), (2.9), (2.3) em leitura, matemática e ciências, respectivamente. Quanto ao desempenho, o país apresentou os melhores índices de evolução quando comparado com os demais. As criações do plano nacional de educação, de avaliações internas do sistema de ensino, como o Índice de Desenvolvimento da Educação Básica (Ideb), foram políticas públicas adotadas no país que tem surtido efeitos positivos nos resultados internacionais. Porém, o país é o único entre os sete que não obteve melhora nos resultados na avaliação de 2015 em relação a de 2012, fato que seguiu a mesma tendência quando considerado a evolução do PIB de 2012 para 2015, conforme apresentado na Tabela 5.

Quanto aos valores descritivos do Índice econômico, social e cultural (ESCS), estes podem ser observados na Tabela 29.

Tabela 29. Valores Médios do ESCS dos estudantes para os países selecionados

\begin{tabular}{|c|c|c|c|c|c|c|c|c|}
\hline \multirow{2}{*}{ País } & \multicolumn{2}{|c|}{2006} & \multicolumn{2}{|c|}{2009} & \multicolumn{2}{c|}{2012} & \multicolumn{2}{c|}{ 2015 } \\
\cline { 2 - 9 } & Média & D.P. & Média & D.P. & Média & D.P. & Média & D.P. \\
\hline Argentina & $-0,94$ & $(1,16)$ & $-0,78$ & $(1,18)$ & $-0,61$ & $(1,11)$ & $-0,79$ & $(0,40)$ \\
\hline Brasil & $-1,30$ & $(1,30)$ & $-1,19$ & $(1,21)$ & $-1,07$ & $(1,18)$ & $-0,96$ & $(0,30)$ \\
\hline Chile & $-0,11$ & $(0,91)$ & $-0,73$ & $(1,13)$ & $-0,30$ & $(1,25)$ & $-0,49$ & $(0,30)$ \\
\hline Colômbia & $-1,37$ & $(1,20)$ & $-1,16$ & $(1,18)$ & $-1,06$ & $(1,10)$ & $-0,99$ & $(0,40)$ \\
\hline México & $-1,18$ & $(1,27)$ & $-1,25$ & $(1,27)$ & $-1,16$ & $(1,24)$ & $-1,22$ & $(0,40)$ \\
\hline Peru & $*$ & $*$ & $-1,34$ & $(1,19)$ & $-1,33$ & $(1,18)$ & $-1,08$ & $(0,40)$ \\
\hline Uruguai & $-0,83$ & $(1,29)$ & $-0,99$ & $(1,18)$ & $-0,87$ & $(1,10)$ & $-0,78$ & $(0,20)$ \\
\hline
\end{tabular}

Fonte: OCDE (2016)

* Dados Não disponíveis

Observa-se a melhoria dos índices na Argentina, Brasil, Colômbia e Uruguai. Isto é, ocorreram nesses países melhoras em termos de as características socioeconômicas das escolas, no perfil socioeconômico e contexto sociodemográfico dos estudantes. Os dados apontam também uma redução do desvio padrão do índice para todos os países, o que indica uma melhora em termos de isonomia entre as escolas e estudantes dos países. Estando assim, os dados de acordo com a proposta política que vem sendo implementada na região.

A análise estatística entre os fatores socioeconômicos, descritos na Tabela 29, com os desempenhos em leitura, matemática e ciências, contidos nas Tabelas 26, 27 e 28, serão apresentados na sequência. Inicialmente, a Figura 2 apresenta o diagrama de dispersão resultante da aplicação da regressão linear múltipla ajustada pelo método dos mínimos, quadrados considerando o resultado do PISA em relação ao Índice ESCS. 
Figura 2 . Diagrama de Dispersão da relação entre PISA e o ESCS dos Países Analisados em Leitura
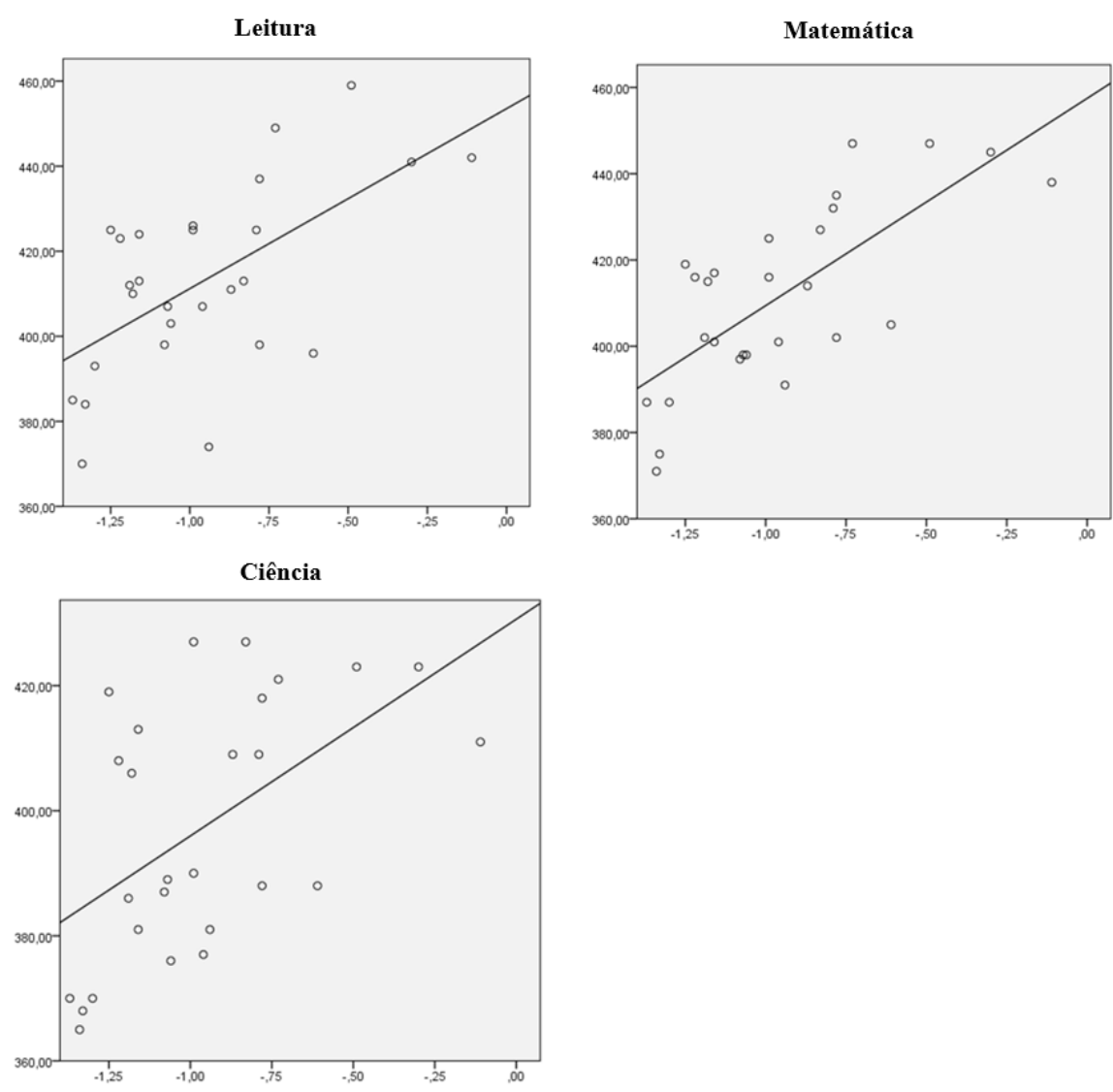

Fonte: Dados da pesquisa

Nos diagramas de dispersão apresentados na Figura 2 as retas observadas consistem na representação do plano cartesiano da Equação 1 após ter os valores das constantes obtidos através do método estatístico aplicado. O eixo horizontal (abscissas) contém os valores do índice ESCS, e o eixo vertical (ordenadas) representa o resultado do PISA das disciplinas avaliadas. Os pontos observados representam a relação entre os valores obtidos no PISA e o índice ESCS de um país para um determinado ano.

Os resultados ilustrados na Figura 2 informam a existência de uma associação progressiva entre as variáveis dependentes e independentes para todas as disciplinas, devido ao ajustamento crescente entre os pontos quando o aumento dos valores do PISA e do ESCS. Essa associação é representada estatisticamente pelo valor $\mathrm{R}^{2}$, que para o modelo em questão, obteve valor igual a 0,141 . Este valor indica, que nos últimos dez anos os fatores socioeconômicos foram capazes de explicar 14,1\% do desempenho do PISA para os países do bloco. Sendo essa relação mais forte para leitura, ciências e matemática, nesta ordem. Também se observou o valor da constante $\gamma$ foi de 26,65 , o que indica que para cada variação de 0,01 ponto no índice ESCS ocorre uma variação média de 27 pontos no PISA e desvio padrão de $(1,60)$.

De forma mais detalhada, a Tabela 30 apresenta a porcentagem da variação no desempenho das disciplinas que pode ser explicado pelo ESCS de forma individualizada por país na última década.

Tabela 30 . Variação entre desempenho do PISA explicada pelo ESCS dos países selecionados

\begin{tabular}{|c|c|c|c|}
\hline País & Leitura & Matemática & Ciência \\
\hline Argentina & $12,3 \%$ & $9,9 \%$ & $11,9 \%$ \\
\hline Brasil & $8,8 \%$ & $13,9 \%$ & $15,7 \%$ \\
\hline Chile & $14,8 \%$ & $8,7 \%$ & $10,9 \%$ \\
\hline Colômbia & $13,9 \%$ & $15,5 \%$ & $10,8 \%$ \\
\hline
\end{tabular}




\begin{tabular}{|c|c|c|c|}
\hline México & $11,7 \%$ & $12,6 \%$ & $12,9 \%$ \\
\hline Peru & $25,1 \%$ & $18,9 \%$ & $20,7 \%$ \\
\hline Uruguai & $14,7 \%$ & $16,7 \%$ & $16,0 \%$ \\
\hline
\end{tabular}

Fonte: Dados da Pesquisa

Os valores contidos na Tabela 30 são resultantes da constante que informa a força da relação entre o nível socioeconômico, representado pela variável ESCS, e o desempenho do PISA. Em outros termos, os dados informam o quanto, em porcentagem, a variável dependente é influenciada pela variável independente. Nesse sentido, podemos afirmar que, por exemplo, na Argentina o desempenho em leitura dos estudantes daquele país foi afetado em 12,3\% pelo nível socioeconômico, sendo as demais variações explicadas por outros fatores não apresentadas no modelo estudado, como gestão escolar, recursos, características das escolas, entro outros fatores.

Em análise aos resultados observa-se, conforme já ressaltado, que o desempenho de leitura é o que sofre maior influência dos fatores socioeconômicos. Resultados estes que corroboram com estudos prévios, que apontam que o conjunto de fatores resultantes do nível socioeconômico determina o desempenho do estudante, principalmente na sua capacidade de leitura e interpretação (BONAMINO et al., 2010).

Destaca-se entre os países do bloco, os resultados obtidos pelo Peru, dado a significativa influência dos fatores socioeconômicos no desempenho dos seus estudantes. O país possui $21 \%$ da sua população residente em zona rural, baixo nível socioeconômico dos estudantes, investiu apenas 3,98\% do PIB em educação em 2015, valor este proporcionalmente inferior a todos os demais países analisados. Dado esse conjunto de fatores, o Peru assume a última posição no desempenho do PISA na América Latina. Por outro lado, a Argentina que apresenta os melhores índices socioeconômicos por estudantes, e maiores taxas de investimento em educação, é o país menos influenciado pela variável socioeconômica.

A Tabela 31 representa a variação do desempenho do PISA derivada da alteração de um ponto percentual da variação do índice ESCE.

Tabela 31 . Variação do desempenho do PISA por unidade de aumento do ESCS

\begin{tabular}{|c|c|c|c|c|c|c|}
\hline \multirow{2}{*}{ País } & \multicolumn{2}{|c|}{ Leitura } & \multicolumn{2}{c|}{ Matemática } & \multicolumn{2}{c|}{ Ciência } \\
\cline { 2 - 7 } & Média & D.P & Média & D.P & Média & D.P \\
\hline Argentina & 26 & $(1,7)$ & 21 & $(1,8)$ & 24 & $(1,5)$ \\
\hline Brasil & 21 & $(1,6)$ & 29 & $(1,9)$ & 31 & $(1,4)$ \\
\hline Chile & 32 & $(1,7)$ & 19 & $(1,3)$ & 18 & $(1,1)$ \\
\hline Colômbia & 31 & $(2,0)$ & 30 & $(1,5)$ & 26 & $(1,6)$ \\
\hline México & 21 & $(1,3)$ & 26 & $(2,0)$ & 24 & $(1,8)$ \\
\hline Peru & 38 & $(1,6)$ & 31 & $(1,5)$ & 29 & $(1,4)$ \\
\hline Uruguai & 35 & $(1,8)$ & 31 & $(2,0)$ & 31 & $(1,4)$ \\
\hline
\end{tabular}

Fonte: Dados da Pesquisa

Os dados descritos na Tabela 31 apresentam importância no sentido de informar o quanto a melhora do nível socioeconômico dos estudantes afeta em valores o desempenho do PISA. Isto é, por exemplo, para cada incremento de 1 ponto percentual no ESCS da Colômbia teríamos uma melhoria de 30 pontos no desempenho do PISA. Entretanto, essa melhoria é limitada ao valor de influência do ESCS sobre o desempenho, conforme apresentado na Tabela 30.

Em análise aos valores apresentados na Tabela 30, temos que o desempenho em leitura seria o mais beneficiado com a melhoria socioeconômica, conforme já apontado nos resultados anteriores. Ainda, em análise em 
conjunto com os dados da Tabela 30, temos que todos os países poderiam aumentar o desempenho do PISA pela melhoria dos fatores socioeconômicos. Situação, que inclusive, vem sendo aplicado no bloco, como por exemplo, por políticas como as brasileiras de renda mínima destinada a população de baixa renda.

\section{Considerações Finais}

O presente estudo iniciou-se com a apresentação da problemática de que países latino-americanos estão situados nas últimas posições no ranking mundial do PISA - especificamente: Argentina, Brasil, Colômbia, Chile, México, Peru e Uruguai. Fato traz consequências negativas futuras para esses países como a redução do nível de produtividade da mão de obra, dificuldade na criação de novas patentes, evolução tecnológica, e resultando, assim, em baixas taxas futuras de crescimento econômico.

$\mathrm{Na}$ sequência, partiu-se para entender a influência dos fatores socioeconômicos sobre o desempenho acadêmico dos estudantes desses países. Utilizando-se dos dados disponíveis pela OCDE, especificamente o desempenho do PISA e o Índice de Status Econômico, Social e Cultural (ESCS). Dado a indisponibilidade de certos dados, o trabalho a apresentou os resultados dos últimos dez anos, ou seja, de 2006 a 2015, uma vez que nas avaliações de 2000 e 2003 quase não houve participação dos países latino-americanos. Sendo assim, este trabalho consistiu em esforço inicial de apresentar a realidade da educação nesses países, permitindo também a comparabilidade entre os resultados.

Os resultados descritivos apontaram que todos os países vêm trabalhando no sentido de melhorar a qualidade da educação oferecidas aos seus estudantes. Nota-se certa convergência nas políticas públicas educacionais adotadas nos países latino-americanos analisados. Destacam-se a universalização da oferta de educação pública e a elevação dos gastos em educação em valores absolutos e como percentual do PIB. Foram observadas reduções significativas das desigualdades socioeconômicas e de desempenho entre as escolas, dado a constante redução dos valores dos desvios padrões das médias dos índices analisados. Fato este que acompanha as políticas que estão sendo implementadas na região, com destaque para programas de descentralização das práticas de ensino para melhor diálogo com a realidade local, programas de formação e aperfeiçoamento docente, investimentos em infraestrutura e modernização e projetos que valorizam a leitura e a maior permanência do aluno na escola.

A análise dos resultados do teste estatístico de correlação, descritos na Tabela 30 e 31, apontaram que o desempenho do PISA sofreu certa influência dos fatores socioeconômicos. Isto é, o desempenho do PISA e o índice ESCS são positivamente correlacionados estatisticamente, conforme pode ser observado nos diagramas de dispersão apresentados. Essa influência é maior no domínio de leitura, ciência e matemática, nesta ordem. Nesse sentido, os resultados vão ao encontro do que vem sendo discutido sobre educação, principalmente nos estudos de economia da educação. Outra importante consideração, é que nos países mais pobres o fator socioeconômico tende a ter maior influência sobre o desempenho.

Entretanto, a influência das variáveis socioeconômicas sobre o desempenho é limitada à média de 14,1\% para os sete países analisados. Isto é, o desempenho acadêmico não é predominantemente explicado apenas pelo índice ESCS. Mas valores baixos para esse índice implicam em entraves na melhoria do desempenho do país, conforme é observado no Peru, por exemplo. Daí a necessidade de se pensar em políticas públicas que melhorem a condição de vida dos estudantes, como meio de se atingir resultados melhores, até certo ponto.

\section{Referências}

ADROGUE, Cecilia. Equality of educational opportunities at public primary schools in Argentina. Education Policy Analysis Archives, v. 21, n. 89, p. 2-28, 2013.

BUSSAB, Wilton; MORET'TIN, Pedro. Estatística básica. São Paulo: Saraiva, 2010.

DE ARMAS, Gustavo; RETAMOSO, Alejandro. La universalización de la educación media en Uruguay: Tendencias, asignaturas pendientes y retos a futuro. Montevideo: Unicef, 2010.

BLOEM, Simone. PISA in Low and Middle

Income Countries. Paris: OECD Education Working Papers, No. 93, 2013.

BONAMINO, Alicia; ALVES, Fátima; FRANCO, Franco; CAZELLI, Sibele. Os efeitos das diferentes 
formas de capital no desempenho escolar: um estudo à luz de Bourdieu e de Coleman. Revista Brasileira de Educação, v. 15, n. 45, p. 487-499, 2010.

CARVALHO, Luís Miguel. Intensificação e Sofisticação dos Processos da Regulação Transnacional em Educação: O caso do programa internacional de avaliação de estudantes. Educação \& Socieadade, v. 37, n. 136, p. 669-683, 2016.

Dirección Nacional De Información Y Evaluación De La Calidad Educativa (DINIECE). Mayores recursos para una educación inclusiva y de calidad. Buenos Aires: Ministério de Educação da Nação, 2013.

DRAPER, Norman R.; SMITH, Harry. Applied regression analysis. Springer Science \& Business Media, 2014.

GORUR, Radhika. As descrições finas das análises secundárias do PISA. Educação \& Sociedade, v. 37, n. 136, p. 647-668, 2016.

FELDFEBER, Myriam; GLUZ, Nora. Políticas para a educação básica na Argentina: os desafios da "inclusão". Retratos da Escola, v. 8, n. 14, p. 65-79, 2014.

GUEDES, Gislaine Nunes; BAQUEIRO, Diciola Figueiredo; LORDÊLLO, José Albertino. Equidade e eficácia escolar: histórico dos estudos. 2015. Disponível em < http://www. equidade.faced.ufba.br/sites/equidade.oe.faced.ufba. br/files/equidade_e_eficacia_escolar_-_historico_ dos_estudos.pdf> Acesso em 08 set. 2016.

GONÇALVES, Antonino Lisboa Mena; PARRA, Shirley Rodrigues. O sistema de ensino colombiano. Brasília: Ministério das Relações Exteriores - Departamento Cultural, 2014.

HAIR Jr., J.F.; BLACK, W.C.; BABIN, B.J.; ANDERSON, R.E. \& TATHAM, R.L. Análise Multivariada de Dados. 6.ed. Porto Alegre: Bookman, 2009.

HANUSHEK, Eric A.; WOESSMANN, Ludger. Schooling, educational achievement, and the Latin American growth puzzle. Journal of Development Economics, v. 99, n. 2, p. 497-512, 2012.

Instituto Nacional de Estudos e Pesquisas Educacionais Anísio Teixeira (INEP). PISA. 2015. Disponível em: www.portal.inep.gov.br/pisa. Acesso em 10 set. 2017.
Lopes, Marcos Raposo; Chuc, Paulo Vassily. Educação básica e ensino médio no México: projetos exitosos. Brasília: Ministério das Relações Exteriores - Departamento Cultural, 2014.

Mello, Eduardo Brigidi de. A educação básica e o ensino médio no Chile: a experiência do estado subsidiário. Brasília: Ministério das Relações Exteriores - Departamento Cultural, 2014.

Ministerio De Educación De Perú Y Organización De Estados Iberoamericanos. Sistema Educativo Nacional de Perú. 1994. Disponível em: http:// www.oei.es/historico/quipu/peru. Acesso em: 15 jul. 2017.

MORGAN, Clara; SHAHJAHAN, Riyad A. The legitimation of OECD's global educational governance: examining PISA and AHELO test production. Comparative Education, v. 50, n. 2, p. 192-205, 2014.

Organisation for Economic Co-operation and Development (OECD). Learning for Tomorrow's World- First Results from PISA 2003. Paris; OECD, 2004.

Organisation for Economic Co-operation and Development (OECD). PISA Data

Analysis Manual: SPSS and SAS,

Second Edition. 2009. Disponível em:

http://www.oecd.org/pisa/pisaproducts / pisadataanalysismanualspssandsassecondedition.htm. Acesso em 01 set. 2017.

Organisation for Economic Co-operation and Development (OECD). Better policies for better lives - The OECD at $\mathbf{5 0}$ and beyond. Paris: OECD, 2011.

Organisation for Economic Co-operation and Development (OECD). Better skills, better jobs, better lives: A strategic approach to skills policies. Paris: OECD, 2012.

Organisation for Economic Co-operation and Development (OECD). Relatório Educação para Todos no Brasil, 2000-2015. Brasília: Ministério da Educação, 2014.

Organisation for Economic Co-operation and Development (OECD). PISA. 2015. Disponível em: www.oecd.org/pisa/. Acesso em 10 set. 2017.

OEI, Organização dos Estados Iberoamericanos. 


\section{Sistema Educativo Nacional de Uruguay.}

Disponível em: http://www.oei.es/historico/quipu/ uruguay. Acesso em: 15 de jul. 2017.

SANTOS, Isabelle Dias Carneiro. A Educação Básica no Brasil: os desafios diante de uma política pública de descentralização e a perspectiva de uma educação federativa e unificada (pp. 21-39). CONPEDI, Anais, 2016.

SELLAR, Sam; LINGARD, Bob. The OECD and the expansion of PISA: New global modes of governance in education. British Educational Research Journal, v. 40, n. 6, p. 917-936, 2014.

Unesco Institute for Statistics. Argentina. Disponível em: http:/ / uis.unesco.org/en/country/ ar. Acesso em 05 jul. 2017.

Unesco Institute for Statistics. Brazil. Disponível em: http://uis.unesco.org/en/country/br. Acesso em 07 de jul. 2017.

Unesco Institute for Statistics. Chile. Disponível em: http://uis.unesco.org/en/country/cl. Acesso em 07 jul. 2017.

Unesco Institute for Statistics. Colombia. Disponível em: http://uis.unesco.org/en/country/co. Acesso em 09 jul. 2017.

Unesco Institute for Statistics. Mexico. Disponível em: http://uis.unesco.org/en/country/mx. Acesso em 09 jul. 2017.

Unesco Institute for Statistics. Peru. Disponível em: http://uis.unesco.org/en/country/pe. Acesso em 11 de jul. 2017.

Unesco Institute for Statistics. Uruguay. Disponível em: http://uis.unesco.org/en/country/uy. Acesso em 11 jul. 2017.

Unesco Institute for Statistics. UIS.Stat - Data.

Disponível em: http://data.uis.unesco.org/. Acesso em 12 jul. 2017.

Vargas, Everton Vieira; Perdigão, Fernando. Educação básica na Argentina: história, estrutura e desafios. Brasília: Ministério das Relações Exteriores - Departamento Cultural, 2014. 